\title{
Sustainability Considerations in Membrane-based Technologies for Industrial Effluents Treatment
}

\author{
Mohammadreza Kamali1,2, Suhas D.P. ${ }^{3}$, Maria Elisabete Costa ${ }^{{ }_{2}}$, Isabel Capela ${ }^{1}$, Tejraj M. Aminabhavi*${ }^{*}$
}

${ }_{1}$ Department of Environment and Planning, Center for Environmental and Marine Studies,

CESAM, University of Aveiro, 3810-193 Aveiro, Portugal

${ }_{2}$ Department of Materials and Ceramics Engineering, Aveiro Institute of Materials, CICECO,

University of Aveiro, 3810-193 Aveiro, Portugal

${ }_{3}$ Department of Chemistry, St. Joseph's College, Bangalore 560-027

4 Pharmaceutical Engineering, Soniya College of Pharmacy, Dharwad, India 580-002

Correspondence to Dr. Tejraj M. Aminabhavi (Email: aminabhavit@gmail.com)

${ }^{*}$ Corresponding authors: Tejraj Aminabhavi (aminabhavit@gmail.com) and Elisabete Costa (Elisabete.costa@ua.pt) 


\begin{abstract}
Treatment of industrial effluents (EFs) from the polluted wastewater sources using membrane technologies is an effective and attractive alternative to overcome the weaknesses of some of the conventional wastewater treatment processes, especially when dealing with EFs loaded with recalcitrant organic pollutants and toxic substances. The application of various polymeric and inorganic membrane based technologies to be used for the treatment of industrial EFs has attracted a considerable attention in the past decades. In this regard, a critical discussion on the sustainability of various aspects of membrane technologies would promote the commercialization of these technologies. In this review, various sustainability criteria in technical, economic, environmental, and social categories have been considered for a critical discussion on the current status and improvement opportunities of membrane technologies for the treatment of industrial EFs. While the application of polymeric membranes has been restricted by some bottlenecks to deal with some industrial effluents, metal oxides fabricated ceramic membranes, and especially those fabricated with nanostructured materials such as nano-zeolites, those made of metal organic frameworks as well as carbon-based fabricated mebranes have shown a promising performance in the rejection of recalcitrant organic pollutants. In addition, the combinations of inorganic membrane technologies with other novel methods such as advanced oxidation processes (e.g., using engineered nanomaterials) can be considered among the best options to deal with such highly polluted effluents.
\end{abstract}

\title{
Keywords
}

Sustainability, Membrane technologies, Industrial effluents treatment, Membrane fouling.

\section{Nomenclature}




$\begin{array}{llll}\text { ANBEMR } & \text { Anaerobic Bio-Entrapped Membrane Reactor } & \text { MFCs } & \text { Microbial Fuel Cells } \\ \text { ANDMBRs } & \text { Anaerobic Dynamic Membrane Bioreactors } & \text { NF } & \text { Nanofiltration } \\ \text { ANMBRs } & \text { Anaerobic Membrane Bioreactors } & \text { OME } & \text { Olive Oil Mill Effluents } \\ \text { AOMRs } & \text { Advanced Oxidative Membrane Reactors } & \text { OP } & \text { Osmotic Pressure } \\ \text { AOPs } & \text { Advanced Oxidation Processes } & \text { PAC } & \text { Powdered Activated Carbone } \\ \text { AOXs } & \text { Adsorbable Organic Halides } & \text { PBR } & \text { Photobioreactor } \\ \text { BECMRs } & \text { Bioelectrochemical Membrane Reactors } & \text { PC } & \text { Photocatalysis } \\ \text { BEMR } & \text { Bio-Entrapped Membrane Reactor } & \text { PE } & \text { Polyethylene } \\ \text { BTFs } & \text { Biotrickling Filters } & \text { PES } & \text { Polyethylsulphone } \\ \text { CANMBR } & \text { Ceramic Anaerobic Membrane Bioreactor } & \text { PHACs } & \text { Pharmaceuticals Active Compounds } \\ \text { CAS } & \text { Conventional Activated Sludge Processes } & \text { P-D RO } & \text { Pressure-Driven Reverse Osmosis } \\ \text { CBA } & \text { Choosing-By-Advantages (Approach) } & \text { PA } & \text { Polyamide } \\ \text { CBM } & \text { Carbamazepine } & \text { PRO } & \text { Pressured-Retarded Osmosis } \\ \text { CEC } & \text { Contaminants of Emerging Concern } & \text { P\&P } & \text { Pulp And Paper } \\ \text { COD } & \text { Chemical Oxygen Demand } & \text { PP } & \text { Polypropylene } \\ \text { CTA } & \text { Cellulose Tri-Acetate } & \text { PPCPs } & \text { Pharmaceuticals and Personal Care Products } \\ \text { DCF } & \text { Diclofenac } & \text { PSF } & \text { Polysulfone } \\ \text { DOCs } & \text { Dissolved Organic Compounds } & \text { PVDF } & \text { Polyvinylidene Fluoride } \\ \text { EAOPs } & \text { Electrochemical AOPs } & \text { RO } & \text { Reverse Osmosis } \\ & & & \\ \text { (n) } & & & \end{array}$




\begin{tabular}{|c|c|c|c|}
\hline EAOP & Electrochemical Advanced Oxidation Process & S-MFC & Sludge Microbial Fuel Cell \\
\hline $\mathrm{EF}_{\mathrm{S}}$ & Industrial Effluents & SMPC & Soluble Microbial Products \\
\hline EPS & Extracellular Polymeric Substance & SMSMBR & Salt Marsh Sediment Membrane Bioreactor \\
\hline FO & Forward Osmosis & SRT & Sludge Retention Time \\
\hline HF-MBRs & Hollow-Fiber Membrane Bioreactors & TFC & Thin Film Composite \\
\hline HRT & Hydraulic Retention Time & TCS & Triclosan \\
\hline $\mathrm{H} \& \mathrm{~S}$ & Health And Safety & TFCMs & Thin Film Composite Membranes \\
\hline ICP & Internal Concentration Polarization & TMP & Trans-Membrane Pressure \\
\hline IP & Interfacial Polymerization & TOC & Total Organic Carbon \\
\hline LCA & Life Cycle Assessment & TOPSIS & Technique For Order of Preference By Similarity To Ideal Solution \\
\hline LCC & Life Cycle Cost & TSS & Total Suspended Solids \\
\hline LMW & Low Molecular Weight & SS & Suspended Solids \\
\hline MBTs & Membrane-based Technologies & UF & Ultrafiltration \\
\hline MSBR & Membrane Sequencing Batch Reactor & VOCs & Volatile Organic Compounds \\
\hline MBPR & Membrane Photobioreactors & VFAs & Volatile Fatty Acids \\
\hline
\end{tabular}




\section{Contents}

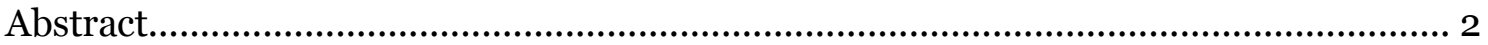

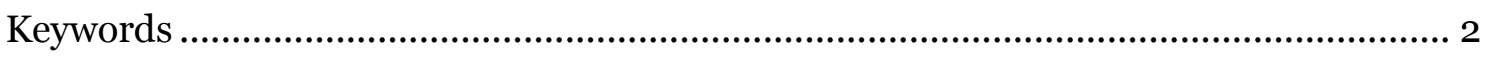

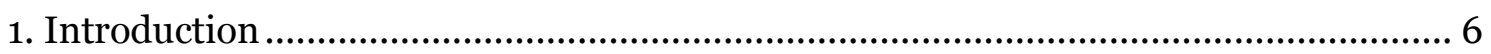

2. Membrane technologies: a brief history ................................................................

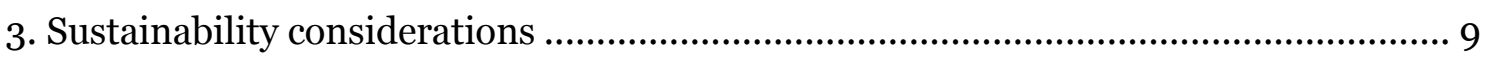

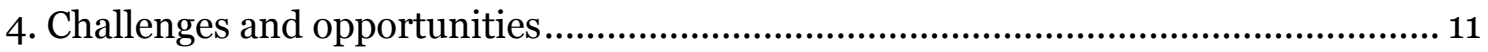

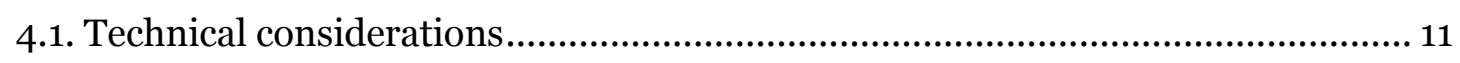

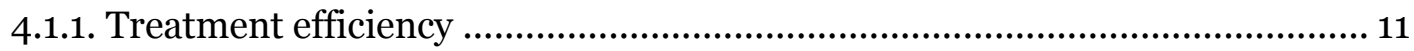

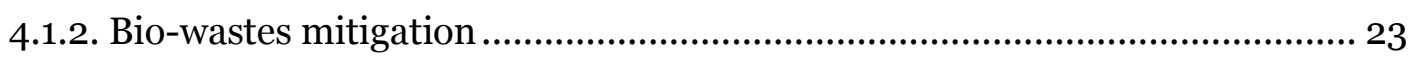

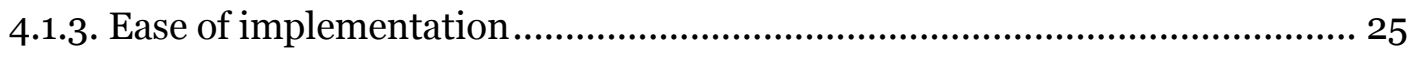

4.1.4. Combination with other methods.......................................................... 25

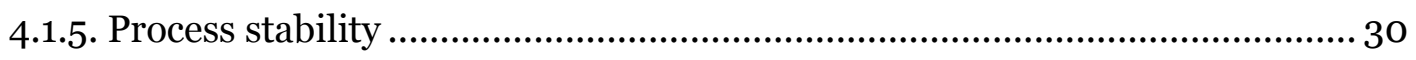

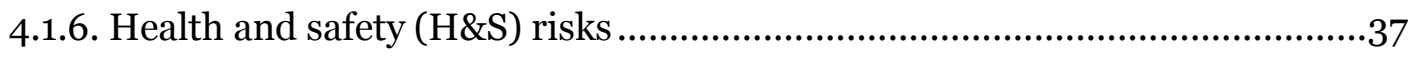

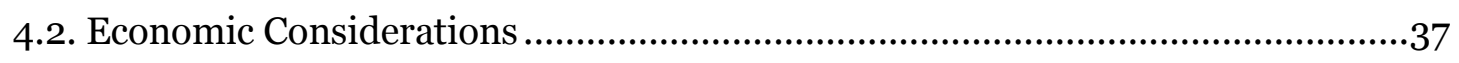

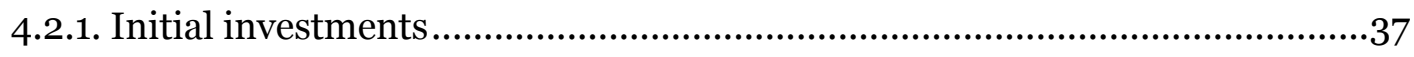

4.2.2. Operating and maintenance costs......................................................... 38

4.3. Environmental Considerations .................................................................... 42

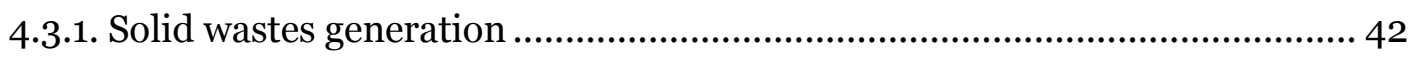

4.3.2. Release of chemical substances............................................................... 42

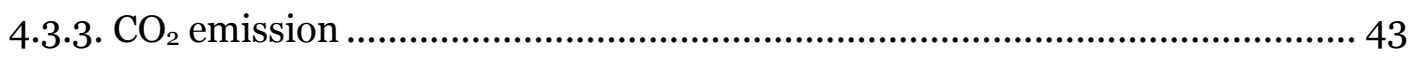

4.3.4. Water reuse potential ........................................................................... 44

4.3.5. Potential to recover by-products ............................................................. 45 
4.4.1. Odor, noise, and visual impacts

4.4.2. Public acceptance

5. Concluding remarks and future perspectives.

References

\section{Introduction}

Rapid industrialization and economic growth have significantly contributed to human welfare in the recent decades in contributing to industrial pollution and eradication of the natural resources around the world [1]. In particular, the generation of large amounts of industrial effluents has considerably stressed the available water resources [2-5], thus raising a great concern not only in developing countries, but also worldwide [6]. There are a number of pieces of evidence for subsequent toxic effects on aquatic organisms when industrial effluents are discharged into the environment without an effective treatment [7-9]. Treatment of industrial effluents is therefore considered a feasible strategy to address this challenge as it also offers the possibility to reuse water, which is of special interest in arid water-scarce countries (e.g., Middle Eastern countries) [10]. In this regard, the development of effective industrial effluent treatment technologies to deal with this problem is among the research priorities within the scientific communities. The presence of recalcitrant contaminants such as adsorbable organic halides (AOXs) and phytotoxic compounds in industrial effluents from various origins makes them resistant to biological degradation and thereby inhibiting the efficiency of biological treatment processes [11].

So far, various methods including physico-chemical (e.g., adsorption, coagulation and precipitation, oxidation, membrane separation, etc.) and biological methods (e.g., aerobic treatment, anaerobic digestion, etc.) or a combination of them have been used for the treatment of industrial effluents [9]. Among the various physico-chemical methods that have been implemented so far to deal with industrial effluents, membrane technologies (i.e., nanofiltration (NF), reverse osmosis (RO), , microfiltration (MF) and ultrafiltration (UF), etc) are still the 
leading methods for addressing the global water shortage problems [12]. Membrane processes are therefore becoming increasingly useful in the treatment of industrial effluents, as well as in the treatment of polluted surface and ground waters, in replacement of many conventional solids/ materials separation processes [13,14]. In addition to the acceptable treatment efficiency of these technologies [15], they can contribute to the recovery of various organic [16] and inorganic compounds $[17,18]$. Although efficiency is one of the most important characteristics of industrial wastewater treatment methods, other criteria ensuring the long-term reliability of a method are equally important. Thus economic, environmental and social criteria have been considered in some studies aiming to identify the most appropriate treatment methods to deal with effluents from different origins.

In this review, we present an overview of the recent findings and developments in the production and application of various types of membrane technologies in order to deal with industrial effluents. For this purpose, a systematic review is organized by considering the sustainability criteria for industrial wastewater treatment. In this regard, a brief history of membrane-based techniques is provided, followed by an overview on the sustainability criteria for industrial wastewater treatment, identified according to the recent literature sources. The criteria so far identified are then used to frame a discussion on the progress, challenges and opportunities of membrane technologies targeted to industrial wastewater treatment.

\section{Membrane technologies: a brief history}

The invention of synthetic membranes goes back to the beginning of the $1900 \mathrm{~s}$. Impregnation of a filter paper with a nitrocellulose solution in glacial acetic acid was the basis of the first synthetic membrane [19]. Such a membrane was then used by Zsigmondy and Bachmann [20] in the ultrafiltration process to separate the macromolecules and fine particles from an aqueous solution. Up to this time, all the membranes had microporous structures. Later on, and with the rapid progress in polymer chemistry, a large number of synthetic polymers were developed, which were ultimately used for the production of polymeric membranes. Such a progress enabled scientists to develop numerous membrane structures with precise properties. The use of membrane technologies for the treatment of effluents thus appeared in the 1950 and was initiated by the success obtained in the application of polymer membranes for the separation of salt from water [21]. 
Progress in the production of RO membranes can be considered a milestone in membrane science and technology. Reid and Breton, [20] developed a RO membrane based on cellulose acetate. They reported both high salt rejection capacity and high flux using this type of membranes at moderate hydrostatic pressures. In the 1950s, some progress in ion exchange membrane technologies took place [23,24], together with a rapid development of the synthetic polymers (e.g., polyethylene, polyamides and polyacrylonitrile), as the basis for the preparation of membrane structures with various properties. One of the most important developments was then the development of pressure-retarded osmosis (PRO), firstly reported by SidneyLoeb, [25]. However, the research in this field slowed down until the 2000s, mainly due to economic considerations [26].

In the 1980 s, interfacial polymerized composite membranes were introduced with advanced properties such as high fluxes, high rejection capabilities, and significantly better chemical and mechanical stability compared to cellulose acetate membranes [27]. Flat sheets and then spiral-wound module structures were the first membranes to be used for RO in 1982 [28]. In 1986, porous membranes were applied for retention of high concentrations of slowgrowing anaerobic biomass in a two-phase anaerobic reactor while keeping low HRT by Fernandes $[29,30]$. In this work, although the membrane had a pore size of $90 \mu \mathrm{m}$, the effluent suspended solids concentration was consistently below $50 \mathrm{mg} / \mathrm{L}$ after 10-15 days of running, with a biomass concentration inside methanogenic reactor up to $30000 \mathrm{mg} / \mathrm{L}$. This could be explained because membranes not only acted as surface filters, trapping particles larger than their average pore size, but also trapped much smaller particulate matter deep in their complex channels, for a "depth filter" effect. It was also stated that, with this liner membrane reactor, without cleaning or replacing, it was not observed a fully block of the $90 \mu \mathrm{m}$ pore, during the 200 days of running, although it was observed a 10\% of flux decrease per month. At that time, the reasons for this were not entirely clear, but it was supposed that it should existed a limiting thickness to the attached/entrapped biomass film on and within the interstices of the membrane structure, above which the film would dislodge. Henc, at the initial stages of the development, membrane performance was limited by fouling, which was divided in two categories, namely cake layer formation on the surface of the membrane and pore clogging, being the first the main contributor to fouling. Later, the development of thin film composite (TFC) architectures $(<200$ $\mathrm{nm}$ ) became a major achievement [31] to deal with this problem. The innovation in inorganic 
membrane structures has also been the important milestone in the field since the beginning of 2000s [12].

Combination of membrane technologies with biological treatment processes is another important development in this area over the two last decades. Membrane bioreactors (MBRs) experienced a period of rapid development around 2009, especially in some developing countries such as China [32]. Currently they are utilized even to deal with persistent environmental contaminants, especially in combination with other treatment methods [33]. Anaerobic membrane bioreactors (AnMBRs) are now widely used for the treatment of industrial effluents, as a consequence of that advancement. This allowed the improvement of MBR performance by working under anaerobic condition. They can bring a number of advantages such as fast start-up, small footprint, high efficiency in terms of total suspended solids (TSS) and chemical oxygen demand (COD) removal, among others [34-36].

In the present scenario, polymeric membranes are at the forefront of the treatment of EFs and the market based on this type of membrane technologies is impressively huge. Research in this field is now focused on addressing the challenges associated with the application of polymeric membranes such as fouling problems and treatment costs. The development of various types of inorganic membrane structures and their combinations with other physicochemical or biological treatment technologies is now the main focus of research in the field of membrane technologies.

\section{Sustainability considerations}

Sustainable development can be defined as "the development that meets the needs of the present without comprising the ability of future generations to meet their own needs" [37]. To attain such a goal, it is vital to consider an integration of environmental, social, economic and technical aspects of the desired activities [38-40].

Selecting the most suitable and sustainable technologies to deal with organic and inorganic contaminants in EFs to comply with stringent environmental standards is a complex task [9]. A literature review allowed to have a perspective on the criteria that must be considered in order to assess the sustainability of membrane technologies for the treatment of EFs. Although the same sustainability criterium might be considered for the evaluation of the treatment technologies for both industrial and municipal effluents, the relative importance of that 
criterium may vary between the two types of effluents. Relying on a choosing-by-advantages (CBA) approach, Arroyo and Molinos-Senante [41] ranked the most suitable municipal wastewater treatment technologies based on various criteria including treatment efficiency, energy consumption, land area required for the treatment facilities, sewage sludge generation, the quality of thewater for reuse, by-products recovery, reliability, odor impact, noise impact, visual impact, public acceptance, and operation complexity .

Dursun [42] by using a systematic approach of "technique for order of preference by similarity to ideal solution" (TOPSIS) considered various factors such as treatment costs, global warming, eutrophication, land requirement, manpower requirement, reliability, sustainability and flexibility. Such studies emphasize the necessity of considering multiple criteria when developing a technology to deal with industrial effluents. Sustainability in terms of various criteria including technical, environmental and economic aspects for the implementation of a large-scale membrane bioreactor (MBR) plant was also addressed by Chen et al. [43]. Hao et al. [32] compared MBRs to conventional activated sludge (CAS) treatments in terms of sustainability criteria by focusing on parameters such as effluent quality, footprints, capital and operational costs, consumption of energy, and membrane fouling. They concluded that despite the high efficiency of membrane biotechnologies and also their small footprint, they suffer from high energy consumption and operating costs. Tufa [44] considered environmental ethics in the sustainable utilization of membrane-based technologies (MBTs) for wastewater treatment. Mahmood et al. [45] identified the criteria for the assessment of hollow membrane module technologies considering the sustainability criteria for the life cycle assessment (LCA) studies. They proposed a set of criteria based on environmental, economic and social aspects.

In accordance with the literature findings, sustainability criteria for the development of membrane-based technologies targeted to EFs treatment must include technical (i.e., treatment efficiency (TE), ease of implementation (EI), combination with other methods (CM), process stability (PS), and health and safety risks (HSR), economic (i.e., initial investments (II), operating costs (OC), maintenance costs (MC)), environmental (i.e., solid waste generation (SWG), release of chemical substances (RCS), $\mathrm{CO}_{2}$ emission (CE), water reuse potential (WRP), potential to recover by-products (PRB)), social (i.e., odor impact (OI), noise impact (NI), visual impact (VI), and public acceptance (PA)). These were the criteria considered in this review in 
order to have a reliable conclusion on the current status and improvement opportunities of MBTs for the treatment of EFs (Fig. 1).

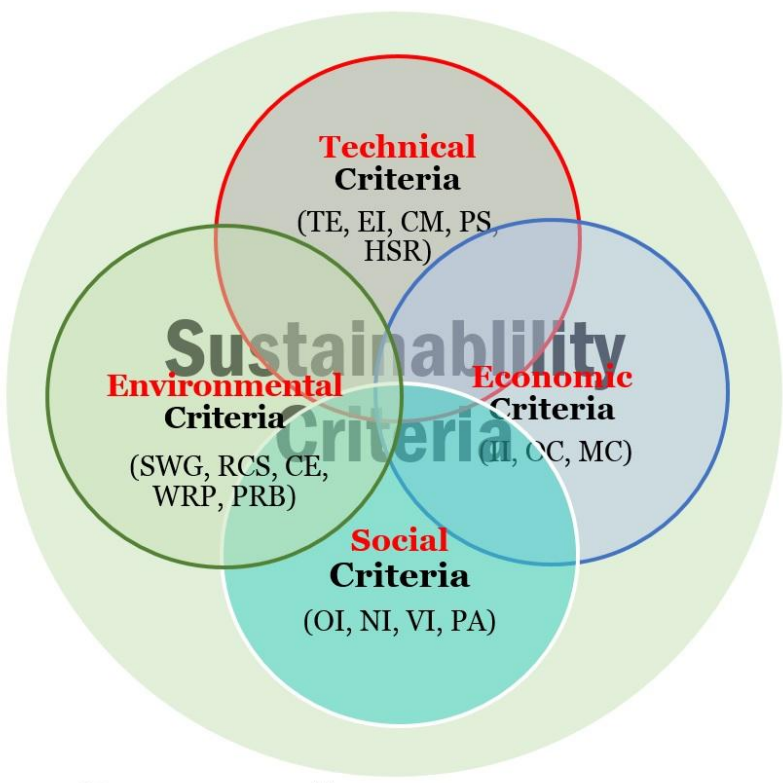

Fig. 1.

Sustainability criteria as considered in this study for the development of MBTs for the treatment of industrial effluents.

\section{Challenges and opportunities}

This section is aimed to address the challenges and opportunities for the development of MBTs for the treatment of industrial effluents. To this end, this section has been organized based on the sustainability criteria and sub-criteria that were discussed in section 3 .

\subsection{Technical considerations}

\subsubsection{Treatment efficiency}

Various types of membrane technologies have been so far considered for their efficiency regarding industrial effluent treatment. Three main mechanisms are generally used for the separation and removal of environmental pollutants using membrane technologies, which are based on (a) size exclusion (or steric hindrance effect), (b) hydrophobic interaction between pollutants and membrane, and (c) electrostatic interactions between pollutants and membranes [46-50]. Size exclusion separates the solutes with sizes larger than the pore size of the membrane. Smaller size solutes may pass through the membrane but larger ones may be retained. Most of the polymeric nanofiltration (NFs) membranes 
[51] have very high hydrophobicities. Hydrophobic organic pollutants with neutral or positive surface charges get adsorbed onto these membranes because of the membrane negative surface charge of the in most environmental situations.

Adsorption is the primary mechanism for the rejection of low molecular weight (LMW) hydrophobic (mainly organic) solutes. However, they will ultimately be rejected by size exclusion mechanism after being saturated [52-54]. Electrostatic interaction of the pollutants with the membrane surface can be directly attributed to both the surface charge of the membrane and that of the pollutants [55]. For instance, TFCs are generally negatively charged at a neutral $\mathrm{pH}$. Sulfonic and/or carboxylic acid groups (with the deprotonation ability at neutral $\mathrm{pH}$ ) are responsible for such a negative charge [56,57]. In such $\mathrm{pH}$ conditions, pollutants with positive charges can be readily adsorbed onto the surface of the membrane and are separated from the wastewater. As discussed by Ganiyu et al. [46], adsorption of positively charged pharmaceutically active compounds (PhACs) onto the membrane surface is an example of this type of mechanism that may apply for the separation of organic compounds from EFs.

Membranes may be classified according to the size of the particle or element to be filtered. The MF membranes are usually suitable to deal with particles in the size range of 100-1000 $\mathrm{nm}$. UF membranes are applied when their size reduces to 5-100 $\mathrm{nm}$ (such as bacteria or viruses), and finally, NF membranes are suitable for the separation of 1-5 nm sized compounds. In the forward osmosis (FO) process [58], a draw solution having a higher osmotic pressure (OP) on one side of a membrane draws the water from the other side (feed solution) with a lower OP. Unlike in the pressure-driven reverse osmosis (P-D RO) energy is applied to drive the osmotic pressure [59]. The performance of a membrane technology directly associated with parameters such as pore size, type and properties of the membrane material (e.g., mechanical strength), and composition of effluents to be treated, as well as operating parameters such as retention time, $\mathrm{pH}$, temperature, etc.

Suhas et al. [6o] and Kim et al. [61] summarized the recent studies to deal with contaminants of emerging concern (CECs) by various membrane processes including FO, RO, NF, and UF. By addressing the physico-chemical characteristics of CECs (i.e., solute molecular weight, size and geometry, surface charge, and hydrophobicity), operating conditions (i.e., $\mathrm{pH}$, solute concentration, operating temperature, etc.), and also the properties of the membranes (i.e., fouling behaviour, pore size, porosity, zeta potential, and strength) they concluded that the efficiency of the membranes for 
EFs treatment followed the sequence: $\mathrm{RO} \geq \mathrm{FO}>\mathrm{NF}>\mathrm{UF}$. Chemical stability is among the most important features in the performance of membranes to deal with industrial effluents, especially under harsh operating conditions. In addition to the materials used, size of the pores can also influence the stability of the membranes, since membranes with very fine structures are of less stability [62].

From the view-point of membrane materials, both polymeric (e.g., polyethylene (PE), polyethylsulphone (PES), polypropylene (PP), polyvinylidene fluoride (PVDF)), and inorganic (ceramic membranes (i.e., metal oxide, metal organic framework, zeolite, carbon-based (i.e., carbon nanotubes, and graphene) materials have been utilized so far to produce membranes for the treatment of EFs. As regards the polymers, innumerable literature reports have been published on the application of various types of polymeric membranes for treating EFs. These polymeric membranes can bring advantages such as selectivity, low cost of operation, ease of preparation, flexibility, and good quality control (for the effluents). However, there are limitations in the performance of these types of membranes such as low thermal and chemical stability, which can cause difficulties for their large-scale applications [63-65].

Lau and Ismail [66] applied NF polymeric membranes to deal with textile effluents, which are highly colored. However, they concluded that it is difficult to have an overall conclusion on the feasibility of this technology for the treatment of textile effluents due to the variations in the composition of such highly polluted effluents.

Hosseini et al. [67] reviewed the recent developments in the polymeric membrane technologies for metal plating wastewater treatment and concluded that such membranes can bring advantages of high separation efficiency. In this study, RO systems have shown separation efficiency typically higher than $90 \%$ to deal with metallic pollutants such as nickel, chromium and zinc. Among the NF membranes, thin-film composite nanofiltration hollow-fiber (consisting of a semi-permeable barrier made by the hollow fibers) membranes can best perform among the polymeric membranes for the treatment of heavy metals, mainly $\mathrm{Cr}, \mathrm{Cu}$ (II), and $\mathrm{Ni}$ (II).

The performance of some polymeric membranes such as complexation-ultrafiltration in which water-soluble polymers are added in the effluent to bind pollutant molecules forming macromolecular complexes [68] can be highly dependent on the operating conditions, especially $\mathrm{pH}$. For instance, chitosan has shown no rejection at $\mathrm{pH}=2$ for $\mathrm{Cu}$, while by increasing the $\mathrm{pH}$ to 
10, complete rejection was observed [69]. Otitoju et al. [70] mapped out the current trends in the utilization of PVDF membranes to deal with oily wastewaters. They concluded that despite the capabilities of PVDFs (such as their anti-oxidation property, good thermal stability and excellent chemical resistance and high efficiency) development of advanced PVDFs with low antifouling properties is highly required to provide an acceptable flux $\left(Q_{p}=F_{w} \cdot A\right.$; where $F_{w}$ describes the water flux rate $\left(\mathrm{kg} \cdot \mathrm{m}^{-2} \cdot \mathrm{s}^{-1}\right), \mathrm{Q}_{\mathrm{p}}$ represents the permeate stream flowrate $\left(\mathrm{kg} \cdot \mathrm{s}^{-1}\right)$, and $\mathrm{A}$ is the membrane area $\left.\left(\mathrm{m}^{2}\right)\right)$.

Other polymeric membranes also suffer from technical issues including high energy consumption (e.g., in RO process), intense membrane fouling (e.g. in RO, NF, complexationultrafiltration, and electro-membranes processes), high operational costs (e.g., in RO, and complexation-ultrafiltration), the need for chemical cleaning (e.g., in complexationultrafiltration, and electro-membranes) and existing issues in module design and process configuration (as in liquid membranes, and polymer inclusion membranes) [67,71].

There are a number of commercialized polymeric membranes in the market [67]. Various methods have been applied for the fabrication of these polymeric membranes. Of these, TFCs are the most widely used polymeric membrane for the treatment of polluted water and wastewater. The main step involved in the fabrication of these membranes is the formation of a very thin polyamide (PA) film on a porous support layer, which is fabricated mainly from polysulfone (PSF) or polyethersulfone (PES). The dry-wet phase inversion technique has been most widely used for the synthesis of the substrate. The top layer is mainly fabricated using interfacial polymerization (IP) process. The strength of these polymeric membranes is highly dependent on the properties and the resistance of the support layer. The properties of the top skin can also determine the efficiency of the membrane in terms of flux and solute rejection. However, the performance of the membrane is also dependent on some other experimental parameters like time, wastewater content, etc. [66].

Efforts have been made to improve the properties of the polymeric membranes. For instance, the inclusion of charged species during phase inversion process can considerably enhance the flux and mitigate the fouling properties. Such species may be grafted into or adsorbed onto the membrane surface. Nanoparticles such as titania, silica, alumina, and silver were also used to decorate onto the membrane surface to reduce membrane fouling [72]. Wang et al. [73] reviewed the possibilities of integrating functional inorganic nanomaterials with 
polymeric membranes to further enhance antifouling properties of such membranes. They concluded that embedding nanomaterials such as sulfated $\mathrm{TiO} 2\left(\mathrm{SO}_{4}{ }^{2-} / \mathrm{TiO}_{2}\right)$ that were synthesized by exposing $\mathrm{Ti}(\mathrm{OH})_{4}$ to a sulfate source followed by calcining [74]), deposited $\mathrm{SiO}_{2}$ nanotubes, solid superacid (defined as a solid with an acid strength higher than the acid strength of $100 \%$ sulfuric acid, which are not dissolved in the medium [75]) porous $\mathrm{ZrO}_{2}$ shell/void/ $\mathrm{TiO}_{2}$ core particles and porous $\mathrm{Y}_{\mathrm{x}} \mathrm{Fe}_{\mathrm{y}} \mathrm{Zr}_{1-\mathrm{x}-\mathrm{y}} \mathrm{O}_{2}$ coated $\mathrm{TiO}_{2}$ solid superacid nanoparticles can considerably enhance the properties (such as antifouling) of the polymeric membranes. Modification of the membrane with advanced functional inorganic nanomaterials can be used to degrade organic compounds through $\mathrm{TiO}_{2}$ photocatalytic properties. Also, inorganic materials embedded into the structure of the polymer membranes can effectively enhance the hydrophilic (and hence antifouling) characteristics of the membrane.

Inorganic ceramic membranes with various configurations such as flat geometry, tubular structure, or ceramic hallow fiber membranes [76] (Fig. 2) have received much greater attention in recent years to deal with industrial effluents, but they are limited mostly in lab and pilot scales. Properties such as high chemical resistance, chemical inertia and easiness to be cleaned $[77,78]$ have enhanced their performance, compared to polymeric membranes. The type of materials used has the dominant impact on the performance of ceramic membranes. Mohsen et al. [76] reviewed various materials for the treatment of EFs from various origins. They concluded that an $\alpha-\mathrm{Al}_{2} \mathrm{O}_{3}$ tubular ceramic UF/NF membrane with an inner layer composed of either $\mathrm{ZrO}_{2}$ or $\mathrm{TiO}_{2}$ [79] is very effective for the treatment of effluents from pulp and paper (P\&P) industry, characterized with high COD, low BOD and loaded with non-biodegradable compounds $[9,80,81]$. Such a combination was successfully applied for the treatment of effluents from a pulp and paper mill with a maximum flux of $52 \mathrm{~L} / \mathrm{m}^{2} \mathrm{~h}$ and organics retention rate of 60-70\% [76]. Post-treatment of P\&P mill effluents by MF and UF has been also been attempted by Neves et al. [82] as efficient technologies for color removal (84\% and $75 \%$ ) and COD removals upto $84.3 \%$ and $80 \%$ using UF and MF membranes, respectively. Multi-channel tubular structures made of $\mathrm{ZrO}_{2}-\mathrm{TiO}_{2}$ ceramic UF have shown the highest performance among other membrane technologies to deal with textile effluents (with a flux of $255.86 \mathrm{~L} / \mathrm{m}^{2} \mathrm{~h}$ and a dye rejection of about 95\%) [83]. Tubular $\alpha-\mathrm{Al}_{2} \mathrm{O}_{3}$ ceramic MF having a pore size of $\geq 0.2 \mu \mathrm{m}$ has provided a water flux of $500 \mathrm{~L} / \mathrm{m}^{2} \mathrm{~h}[84]$.

Conventional methods to fabricate ceramics generally rely on mixing the precursors (e.g., metal oxides or metallic salts) followed by thermal treatment, normally close to $1000^{\circ} \mathrm{C}[85]$. 
Generation of relatively high amounts of chemical wastes as well as the consumption of energy are the main weaknesses of these methods in terms of environmental sustainability. In this regard, there is currently a trend in the literature for the application of green and low-cost methods for the synthesis of advanced nanostructured materials such as aluminium oxide [86] and iron-based nanomaterials $[87,88]$ in order to prepare ultrahigh flux membranes for improving the efficiency of treatment process based on membrane technologies.

Goh and Ismail [12] reviewed the application of various types of inorganic membranes including ceramic membranes (i.e., metal oxide membranes, zeolite membranes, and metal-organic derived ceramic membranes) and carbon-based membranes (i.e., carbon nanotubes membranes and graphene membranes) to deal with industrial effluents. Various types of inorganic membranes, reviewed in their study, have shown acceptable performance typically $>80 \%$ of pollutants rejection and the maximum flux was observed for $\mathrm{Al}_{2} \mathrm{O}_{3}\left(45 \mathrm{o} \mathrm{kg} / \mathrm{m}^{2} \mathrm{~h}\right)$. They concluded that the inorganic materials have the unique properties (such as antifouling characteristics), especially with reduced thicknesses (e.g., interlayer free ceramic membranes, carbon nanotube-based membranes, and graphene membranes) can open a new window to achieve high output potable water production.

Mohsen et al. [76] reviewed the performance of pressure-driven ceramic membranes to deal with various types of industrial effluents. Ceramic MF and UF membranes have also been successfully applied for the treatment of food industry effluents $[89,90]$. The optimum performance of such ceramic membranes has been achieved using $\mathrm{Al}_{2} \mathrm{O}_{3} / \mathrm{ZrO}_{2} / \mathrm{TiO}_{2}$ membranes and those fabricated from the natural clays. For example, a clay-fabricated MF with a pore size of $0.309 \mu \mathrm{m}$ was utilized for the treatment of dairy effluents and achieved $>90 \%$ of COD removal. The highest flux for the treatment of food industry effluents has been also achieved with $\mathrm{ZrO}_{2}-\mathrm{TiO}_{2}$ mono-tubular ceramic UF (95.4-97.7 $\left.\mathrm{L} / \mathrm{m}^{2} \mathrm{~h}\right)[91]$.

In a pilot plant study [92], hybrid NF with RO removed colour and contaminants of a distillery spent wash $>99.8 \%$ of EFs and TDS of $99.9 \%$ by retaining a relatively high flux compared to that of pure water with no fouling. In a further study [93], hybrid ceramic membrane-based MF and electrodialysis (ED) pilot plant was utilized to remove colour and pollutants of the effluents from the paper industry. The hybrid module gave a recovery of $>90 \%$ from the original wastewater. The ceramic MF membrane was able to resist the higher temperature of the discharged effluent. In addition, the permeate was free from suspended colloidal particles. The hybrid process was more efficient than the individual membrane. 
The arsenic removal from drinking water sources is considered a major environmental problem in many parts of the world. The ceramic-based NF was used to remove arsenate ions with a high rejection of 99.8\% [94]. A significant flux was retained in these experiments suggesting that membranes were not affected by fouling phenomenon. Some tubular ceramic membranes used were prepared by thin film coating of their inner surfaces $(35 \mu \mathrm{m})$ using cellulose acetate solution. The 1-channel, 7-channel, 19-channel tubular hollow membranes having an identical pore size of $1.2 \mu \mathrm{m}$ and a porosity of $35 \%$ by volume were used to separate organic contaminants collected from different industrial wastewater sources.

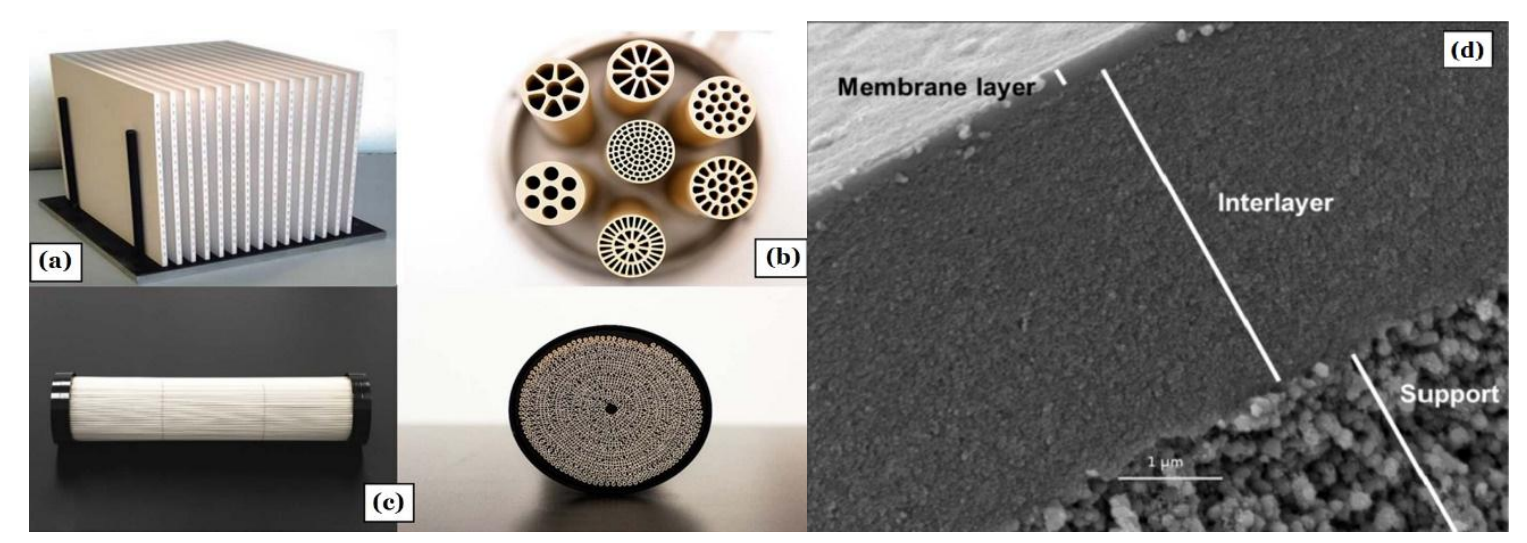

Fig. 2.

Ceramic membranes with various configurations such as flat geometry (a), tubular structure (b), or ceramic hallow fiber (c) membranes are commercially available. Ceramic membranes used for EFs are porous asymmetric structures composed of porous support layers, an intermediate layer as well as a thin top layers as skin (d), adapted from [76].

In conclusion, it must be emphasized that the type of membranes has a crucial effect on their performance and their fouling properties. Although polymeric membranes are the good candidates for industrial wastewater treatment, especially due to their low production costs, they mainly suffer from rapid fouling, which may result in system failure (see 4.1.4). Although the addition of surface modifiers could overcome this weakness to some extent, fouling is still the main barrier restricting the performance of polymeric membranes. Even though ceramic membranes have been able to address this problem, they are still expensive solutions for real wastewater treatment. Thus, development of cheap methods as well as environmentally friendly precursors can considerably push such membranes for rapid commercialization. However, other parameters such as composition of the effluents can significantly affect the treatment efficiency 
using various types of membrane technologies. Table 4 summarizes the main considerations on the application of various membrane technologies considering their efficiency for the treatment of various types of industrial effluents. 


\section{Table 4.}

Current opinion on the efficiency of various membrane technologies for the treatment of industrial effluents.

\begin{tabular}{lll}
\hline Membrane category & Effluents & Remarks and future perspectives \\
\hline - Inorganic membranes & - IEs & - Inorganic membrane technologies have shown their high performance to [12] \\
& deal with the wastewater from various origins. \\
& - Main directions in inorganic membrane science and technologies: a) to \\
& enhance the functionality, flux and selectivity of inorganic membranes via the \\
& hierarchical design of individual or hybrid inorganic materials and molecules; \\
& b) development of thin and defect-free support for membranes or interlayer- \\
& free membranes; c) fabrication of free-standing carbon-based membranes. \\
- TFC, cellulose tri- & The efficiency of the studied membranes for the EFs treatment is as follows: [61] \\
acetate (CTA), triclosan & RO $\geq$ FO $>$ NF > UF. \\
(TCS), & The TFC membranes showed greater retention than the other studied \\
(CBM), diclofenac (DCF) & membranes. \\
- Submerged membrane - Municipal and industrial & - An acceptable nitrogen and phosphorous removal can be achieved (up to [95]
\end{tabular}


- RO systems have shown separation efficiency typically higher than 90\% to deal with metallic pollutants such as nickel, chromium and zinc.

- Some properties of the materials such as chemical, thermal and mechanical stability as well as reasonable procurement cost are essential for the performance of polymeric membranes.

- Polymeric membranes currently suffer from some weaknesses such as high fouling rate due to their hydrophobic characteristics (especially in case of PE), high operating cost, etc.

$97 \%$ and up to $93 \%$, respectively) and simultaneous algal cultivation can be achieved.

- It is still difficult to have an overall perspective on the feasibility of the

polymeric membranes for the treatment of textile effluents because of the variations in the composition of such effluents.

- Embedding the nanomaterials can considerably enhance the properties [73] 
(such as antifouling) of the polymeric membranes.

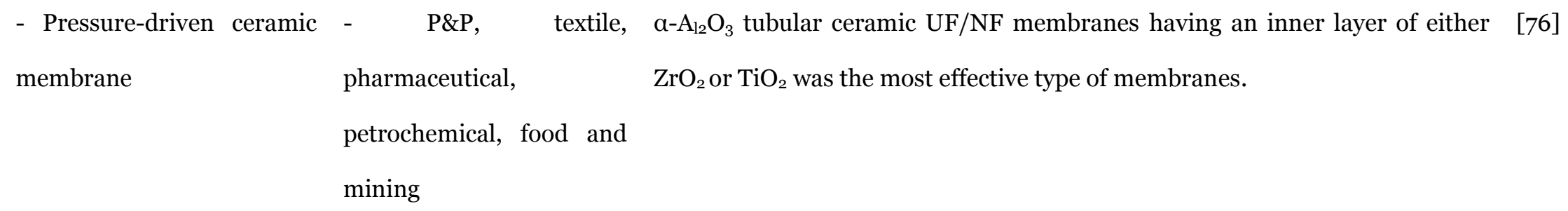

membrane $\quad$ pharmaceutical, $\quad \mathrm{ZrO}_{2}$ or $\mathrm{TiO}_{2}$ was the most effective type of membranes.

- Graphene membranes

- Not specified

PVDFs
Oily wastewaters stability, nanosized pores, atomic thickness, and reactivity toward polar and non-polar water pollutants.

More studies are required to develop advanced PVDFs with low antifouling [70] properties. 


\subsubsection{Bio-wastes mitigation}

Bio-wastes can be defined as agricultural residues, municipal solid waste, wastes and residues from wood industry, animal manure, etc. [97]. There have been several attempts in the treatment of bio-wastes using membrane technologies that have inspired the development of industrial effluents treatments from various origins using membrane technologies. Because of the increasing interest in the use of environmentally benign technologies that can combine biological methods with other treatment technologies, the MBR is considered to be more effective than the conventional wastewater treatment approaches based on activated sludge, especially while treating the micro-pollutants containing wastewaters [98]. MBR systems commonly used UF or MF membranes, hallow fiber, plate and frame configuration, flat sheet or tubular modules.

Jeong et al. [99] through the treatment of food wastes recycling effluents by a ceramic (submerged flat-sheet) anaerobic membrane bioreactor (CAnMBR) (Fig. A.1) reached high degree of treatment efficiency to deal with a high organic effluent at a relatively short hydraulic retention time (HRT). Such a combination was also very beneficial to reduce the fouling of the membrane through efficient conversion of organic materials to biogas ( $0.21 \pm 0.1 \mathrm{~L} \mathrm{CH}_{4} / \mathrm{g}$ COD removed) by anaerobic microbial communities. The system showed stable performance in terms of flux (> 9.2 $\mathrm{L} \mathrm{m}^{-2} \mathrm{~h}(\mathrm{LMH})$ ) maintained at an HRT of $13 \mathrm{~h}$ for 200 days without the need for any chemical cleaning.

A CAnMBR was also applied by Cho et al. [100]. Application of alumina-based flat-sheet ceramic membrane (having a mean pore size of $0.1 \mu \mathrm{m}$ with a total effective area of $0.2 \mathrm{~m}^{2}$ ) has a high degree of stability and provided both high flux $\left(\geq 6.9 \mathrm{Lm}^{-2} \mathrm{~h}^{-1}\right)$ and low fouling properties in the treatment of domestic effluents, as a main source of bio-wastes. In addition, the system resulted in efficient removal of organic compounds ( $\geq 98.0 \%$ ). Application of full-scale MBRs for the treatment of bio-wastes has shown high potential of such combinations for the treatment of the effluents loaded with recalcitrant pollutants. Predictions indicate that there will be a trend over the next 20 years to increase bio-wastes production and their occurrence in landfilling sites [101]. Leachate generation is considered a consequence of the bio-wastes decomposition in the landfills [102].

Sui et al. [103] studied the application of full-scale MBR to deal with pharmaceuticals and personal care products (PPCPs) occurred in the content of landfill leachates in a landfill reservoir in Shanghai, China. They found that PPCPs were detectable in the landfill leachate in concentrations 
between 0.39 to $349 \mu \mathrm{g} / \mathrm{L}$. Full-scale MBR (Fig. A.2) showed a high degree of efficiency in the removal of such compounds (to the extent of $10.6 \mu \mathrm{g} / \mathrm{L}$ ) in the treated leachates.

Pharmaceutical effluents, as the main source of bio-wastes, normally contain large volumes of biological substances along with disinfectants and complex organic compounds that could induce threats to the receiving environments such as toxic effects on the aquatic organisms $[104,105]$ and endocrine disruption in human body cells [106]. Some advanced types of MBRs have been developed recently for the treatment of such effluents. Ng et al. [107] developed a bioentrapped membrane reactor (BEMR) as well as a salt marsh sediment membrane bioreactor (SMSMBR) (Fig. A.3) to deal with pharmaceutical effluents containing high levels of COD, salinity and toxicity. While conventional biomass in BEMR resulted in 54-68\% of COD removal, marine bacterial species in the SMSMBR could efficiently decompose the recalcitrant organic compounds efficiently, achieving up to $74.7-90.9 \%$ of COD removal, leading to a noticeable decrease in membrane fouling. MBR technologies working under anaerobic conditions have resulted in both high treatment efficiency and biogas production. For instance, Ng et al. [108] suggested that pharmaceutical effluents with high salinity and COD can be treated by anaerobic bio-entrapped membrane reactor (AnBEMR).

Wool scouring effluents can also be considered as a source of bio-wastes in textile industry effluents. Several efforts have been applied to deal with wool scouring effluents using membrane technologies, especially in combination with other techniques. For instance, a combination of coagulation-flocculation technique with membrane technology has been reported [109] with an ability to recycle $>90 \%$ of water. However, such combinations seem to be yet so expensive to be commercialized rapidly.

Laijiu et al. [110] developed chitosan-based (chitosan/sucrose/polyurethane composite) biomembrane using drop coating method for the treatment of wool scouring effluents. They immobilized Aspergillus Sojae on the membrane in order to produce the flocculent materials by the fungal microorganisms (mainly polysaccharide, protein and organic acid mixture). They found an increase in absorbability of the system with increasing both chitosan and sucrose contents. The bio-membrane system presented a high performance in terms of COD and suspended solids (SS) of the effluents (>95\%). Dairy effluents also contain bio-waste, which need to be treated efficiently before discharging. Sankar et al. [111] observed that biofilm membrane-based bio-reactors are the good candidates to remove organic and nutrient pollutants from the dairy effluents. 
MBRs have been also used for the treatment of sewage sludge, as a source of bio-wastes. For instance, Collivignarelli et al. [112] studied the thermophilic degradation of sludge and aimed towards "zero sludge production strategy". They monitored the concentration of extracellular polymeric substance (EPS) and concluded that foaming process in MBR is related to the presence of EPS soluble protein fraction. In addition, they found that EPS production is reduced by increasing the non-aeration cycle duration. In another recent study, Moñino et al. [113] studied the co-digestion of food wastes with urban wastewater using a SAnMBR. The system indicated an increase in the methane potential of food wastes by 2.9 fold. Such a strategy can be used successfully for the co-treatment of other types of bio-wastes with industrial effluents.

\subsubsection{Ease of implementation}

Ease of implementation may also be considered in the decision-making process in order to adopt appropriate wastewater treatment methods. Membranes are the suitable candidates for various types of plant design mainly due to their compact design and the need for a low degree of maintenance. The operation of membrane systems is generally very simple without requiring the use of specialized knowledge to handle and operate them [114]. Membrane systems can also be built in a modular form which makes them adaptable to the process scale [115]. Bick et al. [116] suggested that the potential users can adhere easily to membrane technologies as a simple and efficient physical barrier, even if it is more costlier than the conventional existing technologies. Le and Nunes, [26] argued that interfacial polymerization technique for the production of TFC membranes is a facile, easy to use, and able to create a very thin $(<100 \mathrm{~nm})$ selective layer of polyamide. However, it must be stated that the combinations of membrane systems with physico-chemical methods, such as advanced oxidation processes, or with biological treatments, such as anaerobic digestion, may bring some difficulties in terms of the scientific knowledge required and implementation detailes.

\subsubsection{Combination with other methods}


New generations of membrane-based technologies, including the combination of membranes with other physico-chemical or biological methods have also proven their efficacy to deal with the industrial effluents. Luo et al. [95] suggested that an acceptable nitrogen and phosphorous removal can be achieved (up to $97 \%$ and $93 \%$, respectively) using the submerged membrane photobioreactor (MBPR), consisting of an enclosed photobioreactor (PBR) [101, 102] with a submerged or side stream

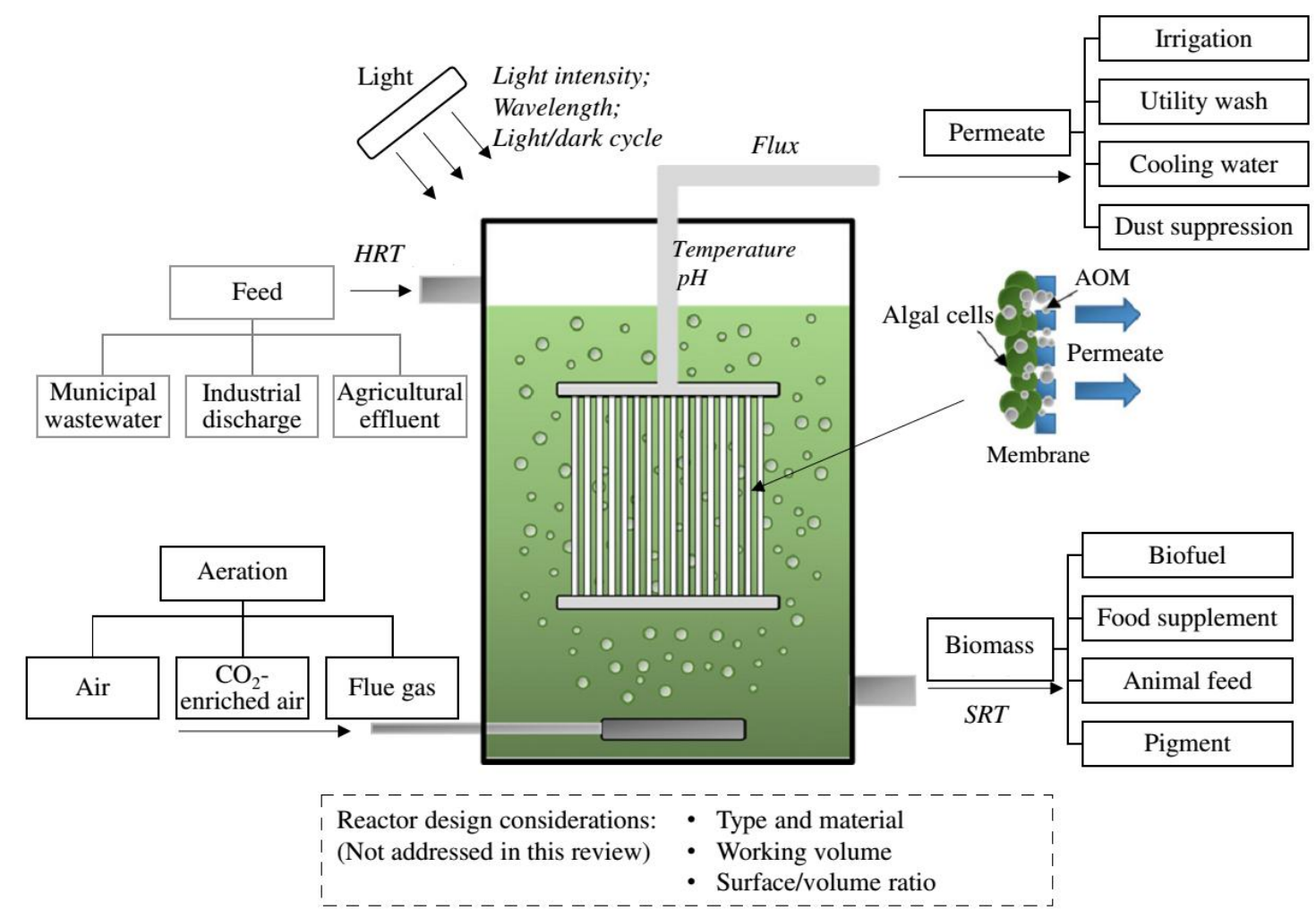

membrane filtration process (Fig. 3).

Fig. 3.

A schematic of the MPBR process, adapted from Luo et al. [95]. The factors which may affect the efficiency of MPBR (i.e., HRT, SRT, flux, temperature, pH, and light properties (e.g., light intensity, wavelength, and light/dark cycles) are indicated in this figure in italic. Corresponding sections (i.e., feed, aeration, light, permeate, membrane and biomass) are also illustrated in boxes.

Even though various studies have indicated the successful application of membrane technologies to deal with a wide range of toxic materials (such as chlorinated organic compounds $[120,121])$, it must be stated that this technique has some weaknesses regarding some dissolved organic compounds (DOCs), especially low molecular weight organic compounds, e.g., in the UF/MF range. On the other hand, advanced oxidation processes (AOPs) have proved their efficiency for the degradation of DOCs. For instance, $\mathrm{TiO}_{2}$ modified with carbonaceous nanomaterials [122] has shown excellent performance in terms of high 
photocatalytic activity, good performance under solar irradiation, and easy to be collected for reuse. It has been well documented in the literature [106-109] that the generation of hydroxyl radicals, as powerful oxidation agents, are the basis of AOPs. Hence, a combination or integration of membrane separation technologies with AOPs (e.g., photocatalytic membrane reactors (PMRs), Fig. 4) seems to be an appropriate solution to enhance the overall efficiency of the process and to overcome the limitations of both AOPs and membranes systems.

Ganiyu et al. [46] reviewed the literature on the combination of AOPs with membrane technologies for the treatment of pharmaceutical residues and indicated the suitability of AOPs (i.e., ozonation, peroxone using $\mathrm{O}_{3}$ and $\mathrm{H}_{2} \mathrm{O}_{2}$, UV/ $\mathrm{H}_{2} \mathrm{O}_{2}$ system, photo-Fenton process, photocatalysis and electrochemical AOPs (EAOPs)) as pre-treatment stages for degradation of organic materials to prevent membrane fouling or as post-treatment stages in order to polish the treated effluents in the membrane systems. Li et al. [127] reviewed the degradation of dyes in the content of industrial effluents by a separation membrane coupled to an electrochemical advanced oxidation process (EAOP). They indicated that such an integration might improve the separation process as long as the operating parameters such as initial dye concentration, current density or electric field intensity, supporting electrolyte nature and concentration, $\mathrm{pH}$, and temperature of the solution are suitably controlled. Furthermore, some important features have to be addressed for the successful combination of membrane technologies with other physicochemical or biological treatments.

The application of pre-treatment step before membrane treatment can potentially enhance the overall efficiency and, may even prevent the system failure caused by membrane fouling. Such combinations were initiated in the 1980s. Canepa et al. [128] applied an integrated three-phase process (UF to adsorption to RO) at pilot scale to deal with OME. The interest in using membrane processes for the separation of volatile fatty acids (VFAs) from the fermentation broth has been well documented [129]. Among the membrane processes, ED has been tested by Scoma et al. [130] for the first time to separate the VFAs enriched effluent from the pre-treated fermentation of olive mill wastewater. Stoller and Bravi [132] studied various methods including coagulant-flocculants, photocatalysis (PC) using titanium dioxide nanomaterials (anatase) under UV light irradiation, and aerobic digestion (AD) to pre-treat OME before batch MF, UF and NF processes in sequence, with a final RO step. They concluded that all the pre-treatment processes are successful leading by $\mathrm{UV} / \mathrm{TiO}_{2} \mathrm{PC}$. Lu et al. [133] summarized the results of the studies on the combination of membrane-ozonation processes for the 
removal of PhACs. They highlighted that a post-treatment to $\mathrm{NF}$ by ozone $\left(\mathrm{UV}_{245} / \mathrm{O}_{3}\right)(4 \mathrm{mg} / \mathrm{L})[134]$ could result in $\geq 99 \% \mathrm{PhACs}$ removal using such a combination. They also emphasized the successful combination of membrane technologies with Fenton and photo-Fenton processes [83], membrane/photocatalytic processes (e.g., with $\mathrm{TiO}_{2}$ nanoparticles) [135], as well as electrochemical treatment processes [133].

Membrane bioreactors (MBRs), composed of filtration processes and biological treatment methods, have also been applied successfully for the treatment of high strength EFs. Sabrina et al. [62] reviewed MBRs performance for the treatment of textile and food mills effluents and concluded that these are the acceptable options for the treatment of high strength industrial wastewaters. One of the main advantages of such combinations is the elimination of the need for large clarifying basins required in some biological treatment methods such as conventional activated sludge processes (CAS) used to ensure complete settlement of the flocs. When CASs are combined with membrane technologies, no more settling processes are required eliminating the area needed for installation of clarifiers [136].

Luo et al. [95] recently reviewed studies on microalgae cultivation as well as the treatment of effluents in MBPRs, which is an emerging and interesting area in the algal research field. Such a combination can bring a number of advantages over the conventional membrane treatment methods. For instance, by avoiding the washout of the biomass, MPBRs can operate under lower hydraulic retention times (HRTs), which is a very important feature especially in reducing the costs and system footprint. They concluded that MBPR process should contribute to achieving a considerable algal productivity (50-100 mg/Ld), depending on the operating conditions. They also stated that $\mathrm{HRT}=1 \mathrm{~d}$, sludge retention time (SRT) $=15$ to $25 \mathrm{~d}$, the intensity of light $=150 \mu \mathrm{mol} / \mathrm{m}^{2} \mathrm{~s}$, applying an aeration with 2 to $15 \% \mathrm{CO}_{2}$, temperature $=25$ to $35{ }^{\circ} \mathrm{C}$, and $\mathrm{pH}=7$ to 8 are the optimum conditions for algal cultivation. 


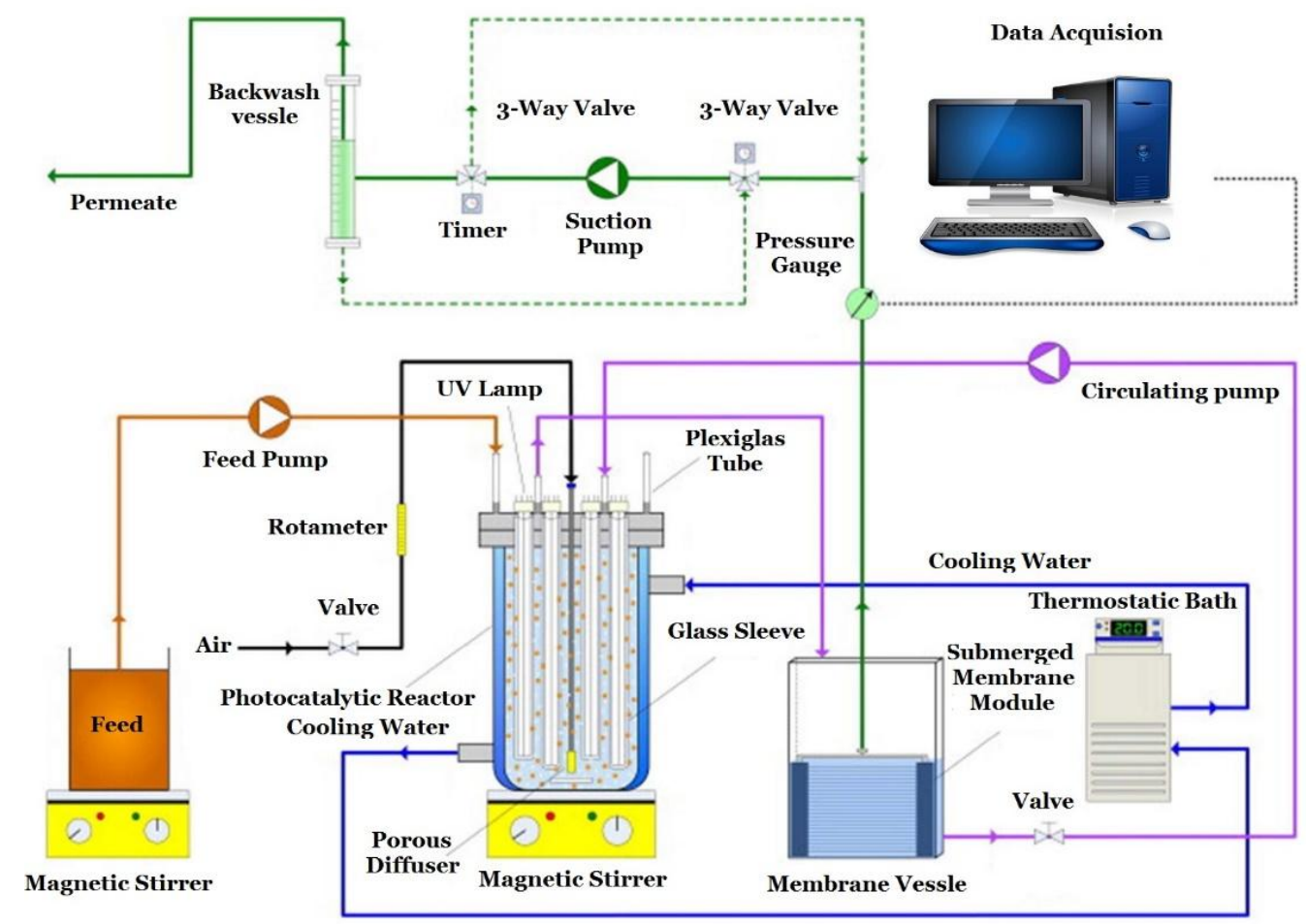

Fig. 4.

A schematic of a photocatalytic membrane reactor (PMR), adapted from Sarasidis et al. [137]. The system has been designed to operate under continuous mode and the membrane vessel as well as photocatalytic reactor are the main components of PMR.

Mitigation of membrane fouling has been considered another reason for the combination of membrane technologies with other physico-chemical or biological methods. For instance, the integration of MBRs with FO (to form an osmotic membrane bioreactor) has contributed to reduce membrane fouling by applying osmotic pressure difference, which is driven from FO [138-141]. Such a combination has shown enhanced efficiency for the treatment of EFs [141]. Another innovative combination is the coupling of MBRs with other biological methods, such as microbial fuel cells (MFCs) [142] to form bioelectrochemical membrane reactors (BECMRs) [143]. Using such a technology, biological treatment of industrial effluents can be coupled with electricity harvesting. Anaerobic dynamic membrane bioreactors (AnDMBRs) [36,144,145] are another successful combination of membrane technologies with the biological treatment techniques, which have demonstrated a number of advantages over AnMBRs. Some of the advantages of these techniques include lower nutrient requirement, lower energy requirement, lower temperature sensitivity, higher potential for bioenergy recovery and better overall treatment efficiency [126, 127]. A schematic, of AnDMBRs is shown in Fig. 5 . 


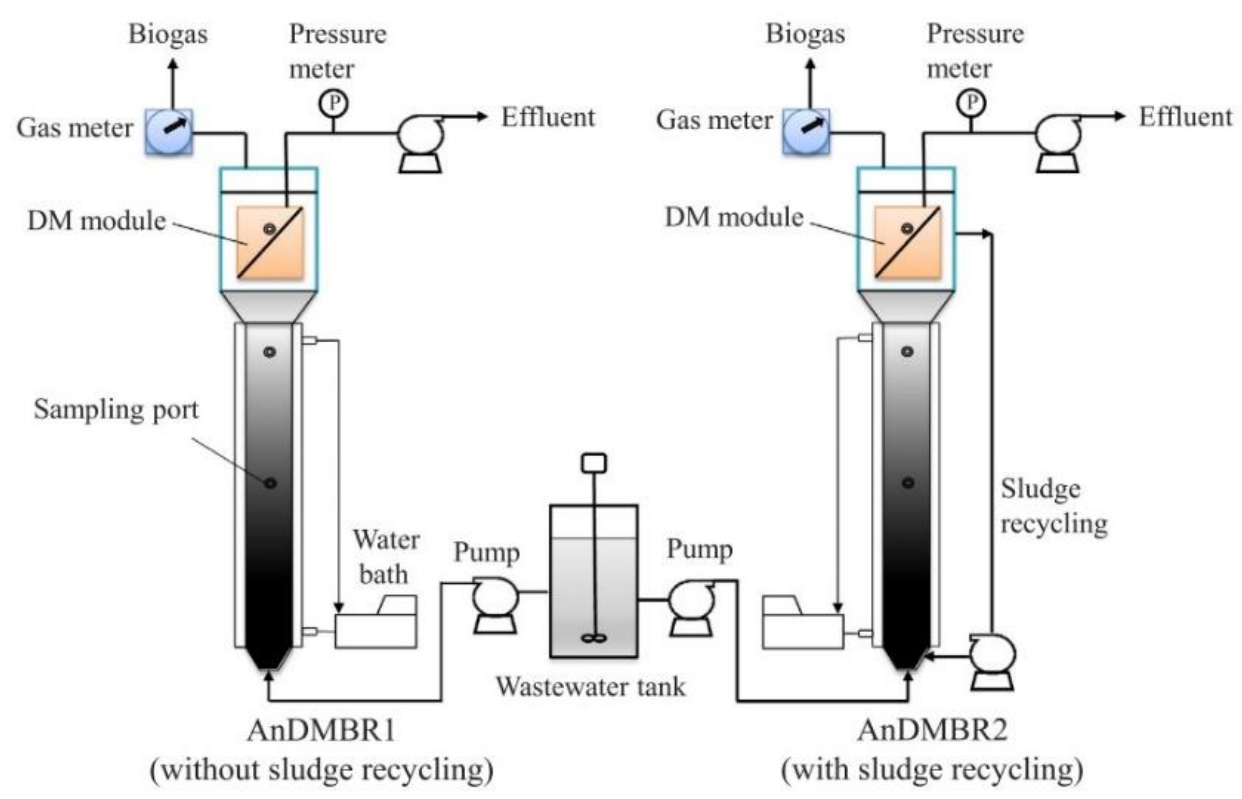

Fig. 5.

A schematics of ADMBRs, re-printed with permission from Hu, Yang, et al. [145]. The AnDMBRs was consisted of an upflow anaerobic bioreactor as well as a submerged dynamic membrane module. In each reactor, a flat-sheet membrane was used. Peristaltic pumps were used to control the feeding rate of the substrate into the reactor and to draw the permeate.

Even though most types of anaerobic bioreactors have been successfully combined with membrane technologies [148,149], only completely stirred reactors and upflow anaerobic sludge blankets have been used in AnDMBRs. Therefore, combination of membranes with anaerobic treatment methods is far from being a mature technology, with a great potential for future growth. Table 5 summarizes the recent studies on the combinations of membrane reactors with other physico-chemical or biological methods.

\subsubsection{Process stability}

Process stability is an important feature for long-term reliability of a method for the treatment of industrial effluents $[150,151]$. The main drawback associated with the performance of membrane technologies is the fouling phenomenon. Fouling process caused by soluble organic compounds, microorganisms, and colloids can increase the feed pressure. 
Table 5.

A summary of the recent studies on the combination on membrane technologies with other physicochemical or biological methods.

\begin{tabular}{llll}
\hline Membrane & Combination status & Effluent & Remarks / future perspectives \\
Technology & Type & \\
\hline
\end{tabular}

- Submerged or side - Coupled with PBR

- Synthetic and real - Nitrogen and phosphorous can be removed using

[95]

stream membrane

effluents. MBPR

filtration process

- Nano-filtration

- AOPs (i.e., ozonation, peroxone

$\mathrm{O}_{3} / \mathrm{H}_{2} \mathrm{O}_{2}$, UV/ $\mathrm{H}_{2} \mathrm{O}_{2}$, photo-Fenton, residues

photocatalysis and electrochemical),

as pre-treatment stages.

- MF, UF and NF in - Coagulant-flocculants,

sequence, and a final RO photocatalysis with titanium dioxide

nanomaterials under UV light

irradiation, and aerobic digestion, as
Pharmaceutical - The ability of AOPs as a pre-treatment stage for

degradation of organic materials to prevent membrane fouling, or as a post-treatment stage in order to polish the treated effluents in the membrane systems was emphasized.
- Olive oil

effluents 
pre-treatment steps.

- Various types of EAOP

membranes

- MF, UF and NF - Combined with various methods - OME membranes in sequence including coagulant-flocculants, and a final RO step photocatalysis (PC) with titanium dioxide (anatase) nanomaterials under UV light irradiation, and aerobic digestion (AD).

$-\mathrm{NF}$
- Dyes in wastewater - Such an integration showed good performance [127] depending on various operational parameters including initial dye concentration, current density or electric field intensity, supporting electrolyte nature and concentration, $\mathrm{pH}$, and temperature of the solution.

- All the pre-treatment processes are successful leaded [132] by $\mathrm{UV} / \mathrm{TiO}_{2} \mathrm{PC}$.

- 99\% PhACs removal can be achieved by this combination.

- Membrane technologies can be successfully 
combined with Fenton and photo-Fenton processes,

membrane/photocatalytic processes and with

electrochemical treatment processes.

- MBRs

- MBRs

- BECMRs

AnDMBRs
- Combination of membrane reactors with biological treatment methods industry effluents

- Combined with FO

- Coupling the MBR and microbial fuel cells (MFCs)

- Combination of membrane reactors with biological treatment methods

- Textile and food - MBRs are good options for the treatment of high strength industrial wastewaters.

- This type of combination eliminates the need for large clarifying basins required in conventional activated sludge processes (CAS).

- The fouling process is reduced by this combination.

- Biological treatment of industrial effluents can be coupled with electricity harvesting, under this combination.

- These techniques are of low nutrient requirement, [146,147] low energy requirement, low temperature sensitivity, high potential for bioenergy recovery and better overall treatment efficiency. 
a. An incorporation of membrane technology in photobioreactor (PBR). 
High fouling rate can rapidly lead to zero the flux conditions and consequently, may result in frequent plant shut-downs if no effective pre-treatment is performed on the raw effluent upstream (see section 4.1.3) [11]. Fouling is thus a barrier that will hinder the performance of polymeric membranes [152-154]. In this regard, various studies have demonstrated that selfcleaning properties and membrane antifouling properties of the polymeric membrane can be improved by utilization of titanium dioxide $\left(\mathrm{TiO}_{2}\right)$ nanoparticles and $\mathrm{UV}$ radiation onto the membrane surface in order to degrade and mitigate organic compounds responsible for membrane fouling [155]. Silica nanoparticles have also demonstrated their ability to be incorporated within the membrane structure as a modifier $[156,157]$ in order to mitigate the fouling properties. This was the case PVDF membranes whose permeability (defined as the flux per pressure $(\mathrm{J} / \Delta \mathrm{P})$ or $\mathrm{LMH} / \Delta \mathrm{kPa})$ and selectivity were increased by the addition of silica nanoparticles. Furthermore, they are the good candidates due to their chemical and thermal stability, while at the same time providing a large surface area with low or negligible environmental drawbacks [70,158,159]. For instance, Zhang et al. [160] reported that phosphorylated silica nanotubes/PVDF composite membranes with low fouling properties can be utilized for the treatment of oily wastewater. Figure 6 illustrates schematics of the interactions between $\mathrm{SiO}_{2}$ nanoparticles and PVDF membrane. The results of their study pointed out around $80 \%$ of improvement in the flux of the membrane compared to control membrane without $\mathrm{SiO}_{2}$.
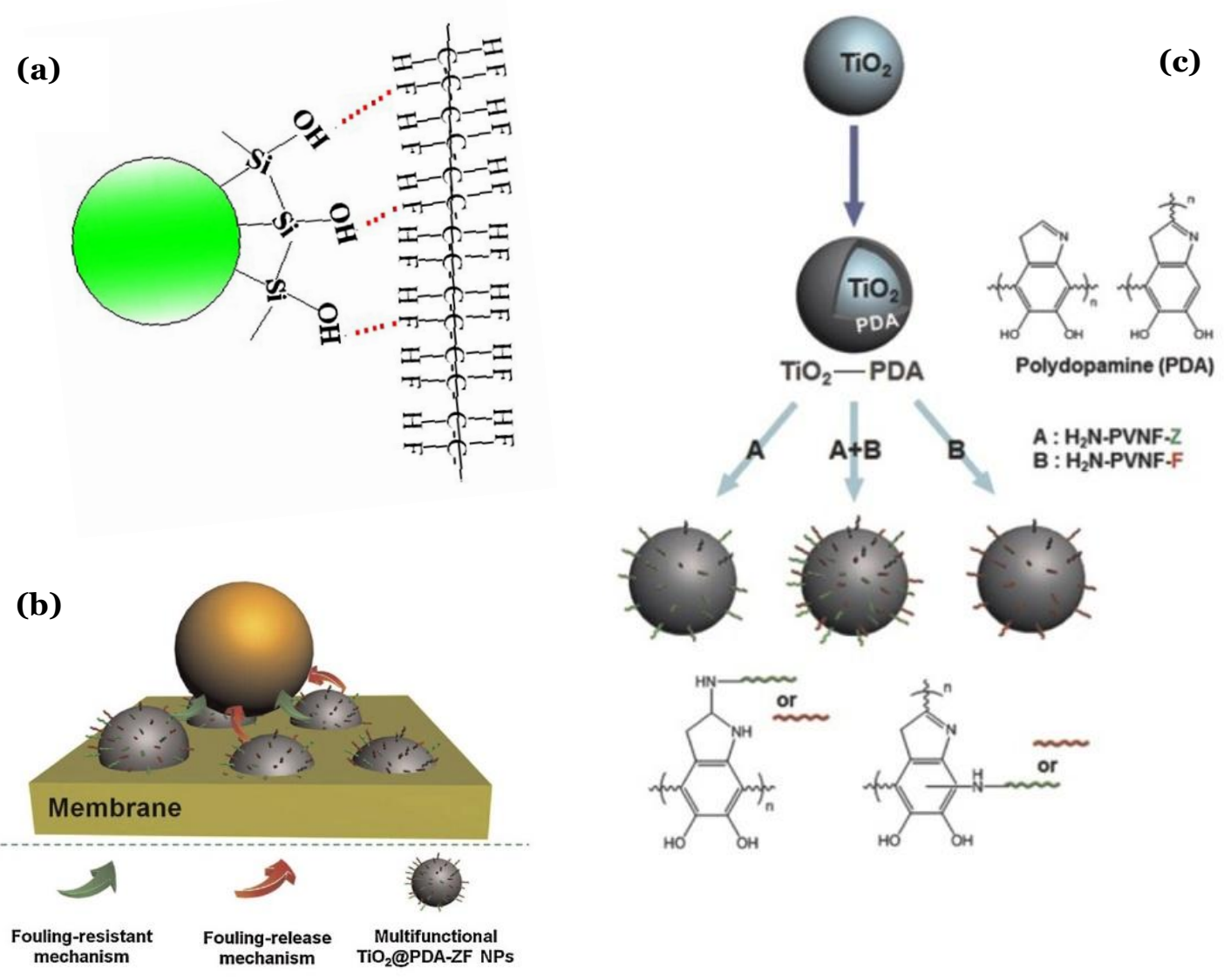
Fig. 6.

A schematic of the interaction between $\mathrm{SiO}_{2}$ nanoparticles and PVDF chains (a). The hydroxylated surface of $\mathrm{SiO}_{2}$, which is not used in the bonding process with the membrane will provide a hydrophilic property to the membrane and this will hinder the fouling process. Heterogeneous hybrid membrane surface with antifouling properties (b). A combination of $\mathrm{TiO}_{2}$ with PVDF membranes (c) [70,160-162].

Other measures have also been adopted in order to increase the antifouling properties of the membranes. For instance, Shahbeig et al. [163] suggested that the addition of low-cost chitosan (4 g/L) in a hybrid membrane bioreactor can potentially prevent membrane fouling (by 42.11\%) through the reduction of soluble microbial products (SMPCs). They also stated that lower operational trans-membrane pressure (TMP) and an increased hydrophilicity of the sludge can also be achieved leading to a better performance of the membrane. It can be concluded that more studies are required to develop cheap and effective solutions for membrane fouling, which is still the main barrier to the development of these technologies.

Some techniques have also been developed to deal with membrane fouling when treating the bio-waste containing effluents. Such methods can be used effectively to enhance the overall treatment efficiency of the membrane-based techniques when treating the effluents with various origins. Chang and Judd [164] applied air sparging technique to control membrane fouling in a submerged MBR (Fig. A.4) for the treatment of domestic wastewater. They applied two different types of sparging techniques, i.e., air injection into the membrane in order to circulate the mixed liquor, and a periodic air-jet into the reactor. They observed that cake layer was removed sufficiently by air injection. However, the air-jet module was not so efficient due to clogging problem. 


\subsubsection{Health and safety (H\&S) risks}

Along with the progress in the development of various types of membrane technologies for the treatment of industrial effluents, possible side-effects resulting from the exposure to membrane structures are also of high importance. Bick et al. [116] stated that for potential users, membrane technologies may be viewed as beneficial for the treatment of industrial effluents, considering the associated low H\&S risks. PVDF membranes have been most widely used for the treatment of EFs. Toxicological studies have shown no toxic effects arising from PVDFs utilization [165]. However, membranes with nanomaterials embedded in their structures must be assessed for their probable toxic effects [26]. Various nanomaterials have been studied so far for the toxic effects they may bring in order to propose safer materials with no or minimum subsequent H\&S effects [166].

ENMs may cross cell membrane under specific conditions and cause harmful effects to the living organisms by inducing oxidative stress and inflammation [167]. The properties of nanomaterials (i.e., shape, size, surface charge, solubility, etc.) can determine their subsequent toxic effects. Recent studies have reviewed the toxic effects that may be induced by nanomaterials [168-173]. Although iron-based nanomaterials such as $\mathrm{Fe}_{3} \mathrm{O}_{4}$ and especially zero valent iron have shown to be the less toxic materials, a consensus about the toxic effects of various types of nanomaterials do not exist among the scientific communities. Hence, there is a need for regulatory framework, which considers all the H\&S aspects of working with nanomaterials $[174,175]$. Also, more studies are needed to assess the H\&S risks that may arise from the application of membrane technologies in factories.

\subsection{Economic Considerations}

\subsubsection{Initial investments}

The initial investments required to implement MBTs for the treatment of EFs can significantly influence the opinion of the decision makers who are looking for the most costeffective solutions to deal with effluents from various origins [176-180]. However, economic feasibility of various treatment methods has not yet been investigated deeply [181]. The costs of land, civil works, equipment, etc. can potentially determine whether a technology will be adopted by an industry or not. Reducing the membrane area required for the treatment of a 
certain amount of effluent is one of the research directions in order to decrease the capital costs of the treatment plants.

Ochando-Pulido et al. [182] applied a batch membranes-in-series processes (including UF followed by $\mathrm{NF}$ and $\mathrm{RO}$ ) for the treatment of effluents from olive mill effluents. They implemented a combined pre-treatment including flocculation process followed by photocatalysis of organic compounds with ferromagnetic-core titanium dioxide under ultraviolet irradiation $\left(\mathrm{UV} / \mathrm{TiO}_{2}\right)$. By using such a pre-treatment, they succeeded to significantly reduce the membrane area (104.6 $\mathrm{m}^{2}$ and $81.4 \mathrm{~m}^{2}$ for UF and NF membranes, respectively), thereby eliminating the need for overdesigning of the membrane plant.

However, the present trend in scientific community is to develop alternative membranes (e.g., inorganic membranes) using cheaper raw materials in order to reduce the required capital costs. Application of the chitosan as cheap raw material to be used as the matrix for the fabrication of inorganic membranes has been recently studied. Basumatary et al. [183] indicated that the application of low cost charged zeolite membranes can be considered a good candidate for the removal of heavy metals (such as $\mathrm{Cr}(\mathrm{VI}))$ from the effluents ( 80\%). Other low-cost options such as chitosan-based membranes [184] can also be considered for such applications although they are in the initial stages of research and development.

Zhu et al. [185] reported the preparation of a $\mathrm{TiO}_{2}$ membrane supported on to mullite hollow fibers synthesized from the industrial solid waste coal fly ash, as a low-cost alternative for the treatment of oily effluents. In another study, Scheibler et al. [186] developed an UF process composed of a low-cost multilayer $\gamma-\mathrm{Al}_{2} \mathrm{O}_{3}$ ceramic membrane for efficient pretreatment of oily wastewater. In addition to the operating costs associated with the membrane, other parameters such as maintenance costs can significantly affect the total costs associated with the treatment plants using the membrane technologies.

\subsubsection{Operating and maintenance costs}

The cost associated with wastewater treatment processes is considered one of the major concerns of the industries all over the world. It is especially important for small mills (such as olive oil industries), which are not able to afford such high treatment costs [11]. Electricity, labour and chemicals costs are the main items to be considered in order to evaluate the overall operating costs. Long et al. [187] stated that the operating costs of centralized wastewater 
treatment plants in industrial parks (case study: Taihu and Haihe water basins (China)) are ranked in the order: electricity $>$ labor $>$ chemical costs.

There are some estimations available in the literature for the operating costs of full-scale membrane technologies for the treatment of EFs [188]. Weschenfelder et al. [189] estimated the operating costs of a full-scale ceramic membrane plant treating oilfield produced water. They stated that under an optimal condition (crossflow velocity of $2.0 \mathrm{~m} / \mathrm{s}$ and water recovery of $95 \%$ ) the operating and total treatment costs are US\$ $0.23 / \mathrm{m}^{3}$ of effluents and US\$ $3.21 / \mathrm{m}^{3}$ of effluents, respectively. Chen et al. [43] evaluated the operating costs of a large-scale membrane bioreactor plant and found that electricity consumption accounts for $51.6 \%$ of the life cycle cost (LCC).

Studies have stated that both high operational costs and energy consumption are required if a high-quality effluent and a smaller footprint of membrane technologies are desired [32]. So, a reduction of the operating costs while maintaining the treatment performance is an urgent need for membrane technologies to meet the current needs of industrial wastewaters treatment. The production costs can be considered as the main parameter influencing the commercialization of newly developed membranes for wastewater treatment purposes. Although some materials such as carbon nanotubes (CNTs) have shown their high performance for the treatment of a wide range of industrial effluents, especially in lab-scale studies, the high production costs of CNTs having high quality is still the main barrier for their widespread applications for real wastewater treatments [190]. Expensive preparation of supports made of $\alpha$ - and $\gamma$-alumina, $\mathrm{ZrO}_{2}, \mathrm{TiO}_{2}$ and glass for conventional metal oxide based inorganic ceramic membranes has also restricted the full-scale application of such inorganic membranes [183].

Cleaning of the membrane is another main source of operating costs. Although some costeffective methods such as application of sodium hypochlorite ( $\mathrm{NaClO}$ ) have been developed, there is a concern for the formation and release of halogenated organic compounds when such materials are used for cleaning purposes [191]. Chemical cleaning has been the widely used process so far for recovering the membranes [192]. The integration of mechanical cleaning with membrane technologies can also open-up a new opportunity for the development of membrane technologies for EFs treatment while minimizing the operating costs associated with the frequent cleaning needs [193,194] and allowing high fluxes. In recent years, other methods such 
as the application of inorganic materials have also been applied to mitigate the operating costs by decreasing the fouling phenomena [195].

Membrane fouling is thus the main drawback of membrane technologies that may bring considerable maintenance costs. Two main phenomena are responsible for membrane fouling that can dramatically affect the performance of the membranes for the treatment of EFs. The first phenomenon is the internal concentration polarization (ICP) (denoting a part of the polarization resulting from changes in the electrolyte concentration due to the passage of current through solution interface) [196-198], which generally occurs over the surface of membranes when the concentration of solutes increases near the membrane surface. In some cases, a gel layer is formed near the membrane surface, when the concentration of the solutes reaches high values. The solutes (or the gel layer) may deposit onto the membrane surface. In this condition, cleaning may be difficult, but possible. There are some reports in the literature for instance to mitigate this phenomenon by the modifications in membrane structure (see Fig. 7). The second phenomenon happens when the concentration of solutes exceeds the solubility concentration. In this situation, the precipitation of solids occurs and they stick to the membrane surface. In this case, the irreversible fouling happens [11].

Bagheri and Ahmad [195] after reviewing the fouling mitigation technologies, concluded recently that the application of methods such as electrical and mechanical approaches, engineered nanomaterials, ultrasonic irradiation, and their combinations with biological treatment methods can be utilized as the effective strategies to deal with fouling and mitigate the associated operating costs. However, none of these methods has yet been applied in full-scale to prove their efficiency with real industrial effluents, thus warranting more research studies to investigate the real effects of such cleaning methods for real applications. Integration of membrane technologies with bioelectrochemical systems (such as MFCs) can also be considered as another possibility to reduce the operating costs through the generation of energy as a result of the decomposition of organic compounds in the context of industrial effluents [194,199,200]. 

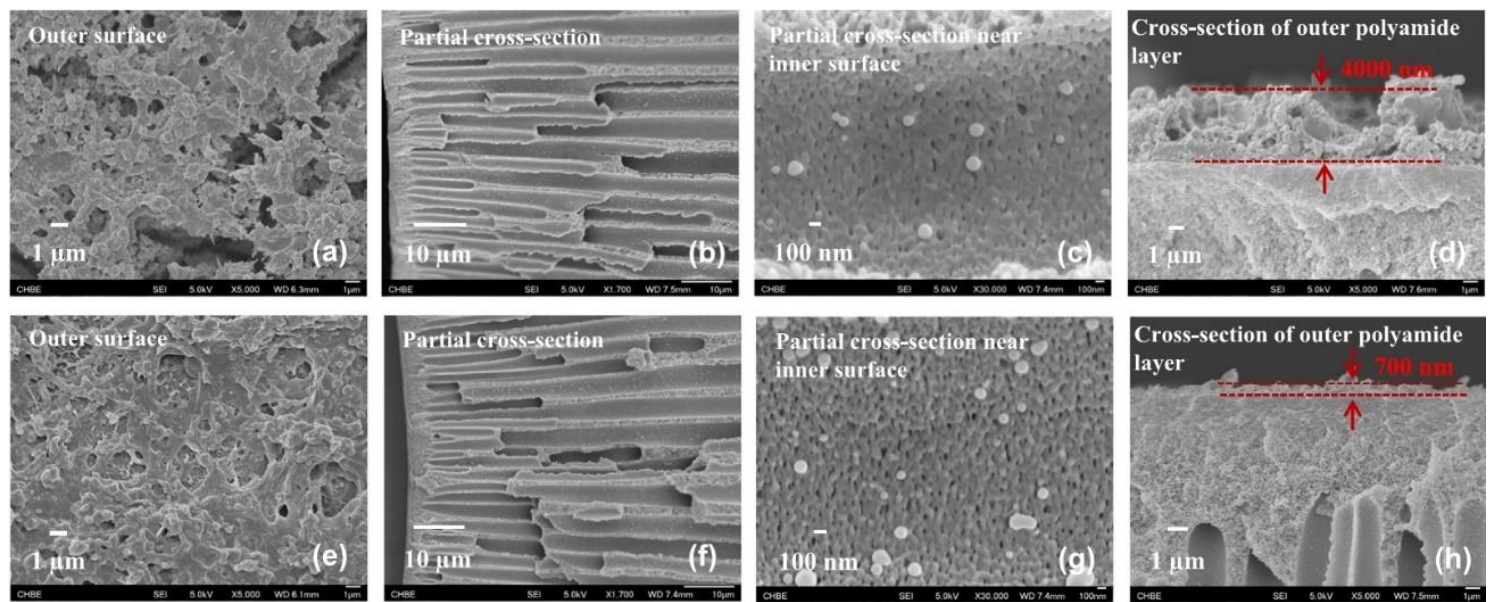

Fig. 7. A TFC hollow fiber membrane. The membrane consists of an inner selective skin and an outer sealing layer both made of polyamide. A double interfacial polymerization process on a tailored polyethersulfone (PES) fiber substrate (dTFC-PES) was applied to fabricate the membrane. In this figure, the outer surface and the cross-section morphology of (a-d) fouled and (e-h) cleaned dTFC-PES hollow fiber membranes have been presented. A Flush process was applied to clean the fouled outer surface with freshwater $(6 \mathrm{~h})$ [197].

Application of bacteriophages in membrane-based technologies is another possibility in order to deal with membrane fouling phenomenon, and also for monitoring the membrane performance and the membrane integrity (Fig. 8, a). Wu et al. [201] reviewed the performance of bacteriophages for this purpose and the existing challenges. They concluded that this process can play an important role in alleviating the membrane fouling through two different life cycles, including lytic cycle and lysogenetic cycle (see Fig. 8, b). 


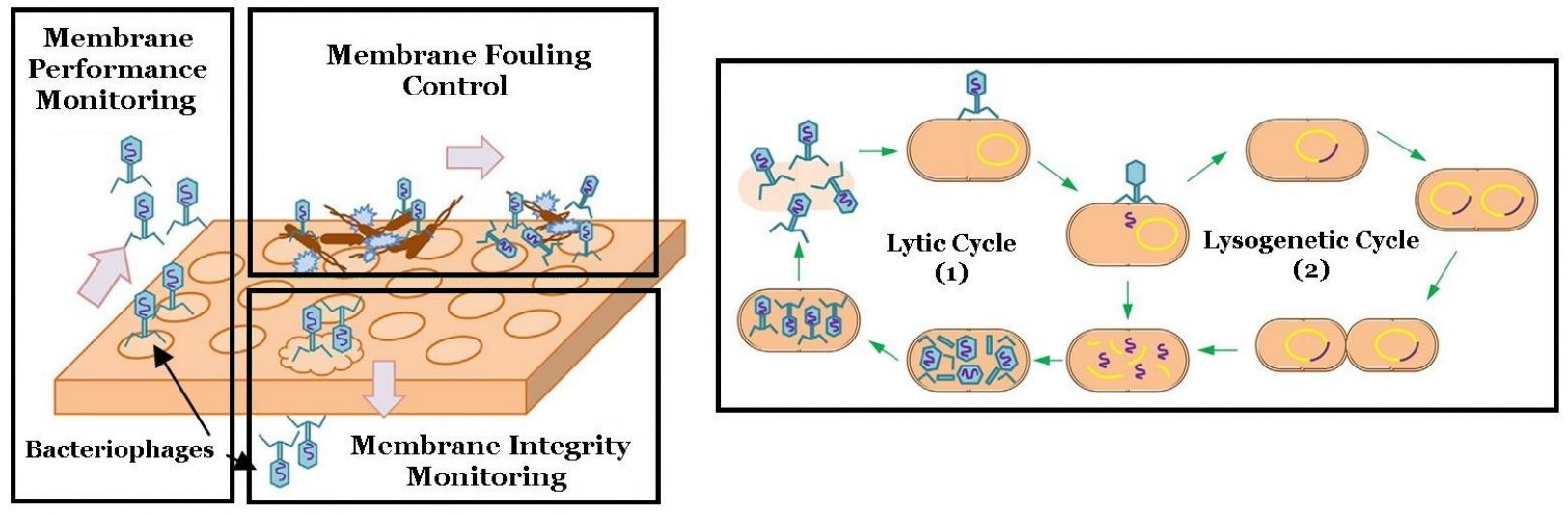

Fig. 8. (Left) Various applications of bacteriophages in membrane-based technologies including membrane performance monitoring, membrane fouling control, and membrane integrity monitoring (left). (Right) The two life cycles of bacteriophages for breaking down the host cells, i.e., lytic and lysogenic cycles (right). The lytic bacteriophages synthesize and assemble new phage particles in the infected cells (1) and then they lyse the host cells (2), adapted from Wu et al. [201].

\subsection{Environmental Considerations}

\subsubsection{Solid wastes generation}

Membrane technologies are among the most outstanding technologies applied so far for the treatment of EFs. However, generation of high amounts of solid wastes (sludge), as a result of the physical separation of contaminants from EFs, is the main drawback of single membrane technologies [202]. In order to overcome this problem, various combined membrane separation technologies have been developed in recent years. Of these, PMR has shown its potential to become a "zero" waste process in the treatment of industrial effluents [203]. Other techniques have also been applied in order to meet such a strategy. The combination of a sludge microbial fuel cell (S-MFC) with an MBR has been studied [204] as another possibility to reduce the pressure on membrane by reduction of the sludge volume and COD of the effluents. In this regard, future studies should be oriented towards the fabrication and development of new generations membrane technologies that will consider both sludge reduction properties and the total cost of the treatment process.

\subsubsection{Release of chemical substances}

As stated before, various types of membrane structures have been tested so far for the treatment of industrial effluents. The possibility of the release of harmful chemical substances from the structure of the membrane is another parameter that can affect both the quality of the treated effluents and the overall treatment costs. Earlier studies have indicated that some 
morphological changes may occur when PVDF is dissolved under harsh environmental conditions (e.g., highly acidic pHs) [205], which can negatively affect the performance of the membrane for the treatment of EFs.

There are some literature reports on the fabrication of polymeric membranes with a high degree of chemical stability. As an example, Ike et al. [206] prepared four different PVDF ultrafiltration membranes from dope (a concentrated polymer solution precursor used in phase inversion method for the preparation of polymeric membranes [207]) dissolved either by stirring at various temperatures or by sonication. Dope sonication resulted in a membrane with enhanced thermal and mechanical stability. The dissolution is also a concern when membranes are decorated with engineered nanomaterials [208]. The extent of ions releasing is directly related to some properties of nanomaterials (such as crystalline structure and particle size), and the operating conditions (such as pH temperature) $[167,209,210]$. Due to the importance of this dissolution on the quality of the treated effluents, and also on the overall treatment cost, there is a need on studies related to the release of toxic chemical substances from the structure of the membranes, particularly under real treatment conditions.

\subsection{3. $\mathrm{CO}_{2}$ emission}

The emission of $\mathrm{CO}_{2}$ may happen under various stages of production, handling, installation and application of membranes for the treatment of EFs. The mechanisms involved in the treatment process can also determine the extent of $\mathrm{CO}_{2}$ released into the atmosphere. Various final products can be expected when different physico-chemical or biological treatment methods are applied. Biological treatment methods can produce various end products such as methane and/or carbon dioxide (in cases of anaerobic digestion and aerobic treatment of organic pollutants, respectively) [211]. However, application of physical treatment methods such as adsorption $[212,213]$ and membrane technologies (as a single treatment method) may separate the pollutants from the liquid phase and concentrate them in the solid phase. Hence, no $\mathrm{CO}_{2}$ release can be expected in these conditions.

Management of the generated solid wastes may include the activities responsible for the release of $\mathrm{CO}_{2}$ into the atmosphere. However, as stated before, novel membrane-based treatment methods are based on the combinations of membranes with other methods such as chemical oxidation (e.g., with nanomaterials [214]) to increase the quality of the treated effluent 
and to prevent the membrane fouling process. In this case, complete oxidation of organic compounds may result in the production of $\mathrm{CO}_{2}$ and $\mathrm{H}_{2} \mathrm{O}$ as final products. In these conditions, the design and implementation of $\mathrm{CO}_{2}$ capturing strategies, e.g., by using ceramic membranes [215] may prevent the release of this greenhouse gas.

\subsubsection{Water reuse potential}

The potential of an industrial effluent for re-use after applying the treatment method(s) is of high importance, especially in terms of environmental considerations. This parameter has been a concern of recent studies on the performance of MBTs, which are the key elements of advanced effluent treatment processes [216]. Various types of membrane structures have so far been considered for their performance to yield high quality water output [217]. Ranganathan et al. [218] indicated the potential of the textile UF and NF processes to yield re-useable water by the treatment of textile wastewater originated from primary dye houses or auxiliary rinse vats. They stated that the treated effluents are generally characterized by low hardness, which is suitable for the re-use in textile facilities. Goh and Ismail [12] by reviewed inorganic membranes for the treatment of EFs and concluded that the application of inorganic membranes with high permeability such as those having reduced thickness (e.g., interlayer free ceramic membranes and free standing carbon nanotubes and graphene-based membranes) can yield a high output of high quality treated water with considerable reduced treatment capital and operating costs. Membrane technologies as combined designs have been also used for the treatment and re-use of industrial effluents. Fakhru et al. [219] indicated that a membrane sequencing batch reactor/reverse osmosis (MSBR/RO) can be used effectively for the treatment of effluents from oil and gas field wastewater with COD, total organic carbon (TOC), oil and grease removal efficiencies of $90.9 \%, 92 \%$ and $91.5 \%$, respectively. They showed that the system reduced both the salt and the organic contents to acceptable ranges suitable for industrial re-use.

Conventional membrane bioreactors (MBRs) have also shown their potential to produce high quality treated effluents having low levels of organic substances, low degree of pathogens and suspended solids $[216,220]$. In conclusion, it seems that membrane-based technologies are the most suitable methods to ensure the required quality to the treated effluents to be re-used at least in industrial applications, which is currently is a sustainable industrial development. 


\subsubsection{Potential to recover by-products}

The potential of a treatment method for the removal and recovery of contaminants such as organic matters and heavy metals may contribute in a sustainable wastewater treatment through simultaneous removal of toxic materials (which can make the wastewater suitable for re-use or discharge) and recovery of the materials, thus aiding to reduce the overall treatment costs $[221,222]$. For instance, the recovery of lignin from pulp and paper mill effluents has been reported in various studies [223] using MF, UF and NF ceramic or polymeric membranes and the recovery of dyes using various types of membranes including MF, UF, NF and MD from the textile mill effluents [224] are few examples. Recovery of heavy metals using membrane technologies is another possibility to increase the overall benefits of the treatment process.

Membranes can also aid to recover nutrients from the effluents. Yan et al. [17] reviewed the nutrient recovery from effluents using membrane-based technologies and concluded that hybrid systems including the integrations of membrane techniques with chemical and/or biological systems (especially bioelectrochemical hybrid membrane technologies) are the promising strategies for the recovery of nutrients from the effluents. In some industries such as the food and beverage industry, membranes have been utilized to recover cleaning agents such as detergents [225]. Membranes can also be used to produce renewable energies. For instance, reverse electrodialysis $[226,227]$ can be utilized in the simultaneous treatment of EFs and the production of electricity. However, the techno-economic features of such advanced types of membrane technologies need to be addressed for their commercialization.

Some reports are available on the valorization of solid bio-wastes in the literature, which can be used to develop MBTs for the treatment of various industrial effluents. Mansour et al. [228] recovered polyphenols from lemon, orange and onion peel extracts using a hybrid molecular imprinted membrane via precipitation polymerization method. In some countries, the disposal of bio-wastes is also an increasing problem due to the shortage of land. Disposal of solid wastes can also considerably increase the nitrate levels in drinking waters [229], which is a great environmental concern.

Membrane technologies can be utilized in order to reduce the dangerous fractions in the content of the solid wastes and to use the remained sludge as compost (after composting) for land fertilization. For instance, this combined method has been applied to deal with pig manure [230] in a special low-pressure MF system. Using such a technique resulted in the $70 \%$ recovery 
of water and production of fertilizers to be used in greenhouses. In another study, Cano and Palet, [231] studied the enzymatic catalyzed hydrolysis of xylan polysaccharide using Endo-1,4$\beta$-Xylanase, embedded in an enzymatic polymeric membrane for the treatment of agricultural biomass wastes (Fig. A.5). In addition to the high efficiency achieved by this module, the short chain xylooligosaccharides were recovered with the potential applications in food and pharmaceutical industries.

\subsection{Social Considerations}

Social criteria including odor, noise and visual impacts and also social acceptance can influence the potential of membrane technologies to be selected for the treatment of EFs.

\subsubsection{Odor, noise, and visual impacts}

In some treatment processes, such as pond systems, the treatment of organic compounds may result in the production of odorous compounds such as volatile fatty acids (VFAs) [232]. In addition, the presence of volatile organic compounds (VOCs), as typical matters in effluents from various industries, can negatively affect the local communities [233]. Hence, the ability of the applied treatment method for minimizing the odorous compounds in the context of effluent with no secondary odor production will increase its acceptability by the local communities. Studies have indicated the capabilities of some of the membrane technologies to mitigate the odorous compounds from EFs and hence, to increase the acceptability of these methods. Schideman et al. [234] indicated the successful removal of 2-methylisoborneol, as one of the main odorous compounds [235] using submerged membranes.

Although the filtration process may result in the rejection of organic compounds (not their degradation), new technologies such as the application of advanced oxidation processes and their combination with the membrane processes may result in the simultaneous rejection and degradation of organic compounds in the context of industrial effluents. Garc1 et al. [236] through a comparative study concluded that biotrickling filters (BTFs) are among the most cost-effective membrane technologies with a high capability to remove VOCs from the effluents. They also indicated that hollow-fiber membrane bioreactors (HF-MBRs) could provide a good performance for the removal of odorous soluble compounds. However, membrane clogging associated with the presence of compounds such as alpha-pinene can adversely affect the performance of membrane bioreactors to remove the odor from the content of industrial effluents [237]. There are also 
some reports in the literature for other successful combinations of membrane technologies with other methods to mitigate the odor. As an example, Bruchet Laîné [238] showed that a combination of NF and powdered activated carbon (PAC) is a very effective way to control the odor of the treated effluents.

Some successful attempts have been made in the removal of volatile solid fractions in the content of bio-wastes, which can be used as a model to deal with industrial effluents. As an example, Trzcinski et al. [239] applied a three-stage membrane bioprocess for the treatment of organic fraction of municipal solid wastes. They indicated that the system successfully removed $75 \%$ out of $75 \%$ volatile solids. The system consisted of an anaerobic hydraulic reactor in order to separate the solids and liquid phases with a mesh. A submerged anaerobic membrane bioreactor was then applied to treat the leachate and the permeate was finally polished in an anaerobic membrane bioreactor.

"Less crowded neighbourhoods" is considered an advantage for certain places to attract the habitants [240]. Various process units in a wastewater treatment plant are responsible for creating noise [241], which may affect the local communities. However, the noise impacts from the industrial effluent treatment plants, which use membrane technologies to the local communities have not yet been well studied.

Aesthetic characteristics of an industry can also highly influence its social benefits [242]. Feasibility of a technology and the design parameters of the treatment units such as size, shape, etc., are of high importance in this regard. As stated before, membranes can be designed with a high degree of flexibility for various types of plant design due to their compact design [114]. So, they may bring low visual impacts in case of incorporating the aesthetic parameters in the plant design process.

\subsubsection{Public acceptance}

Besides the technical, environmental and economic performance of an industrial effluent treatment technology, public acceptance can ensure its long-term sustainability [243]. In other words, an industrial wastewater treatment technology should be beneficial, useful, and necessary enough to be acceptable by the society [244]. The footprint of a technology can be directly correlated with its public acceptance. In this regard, some studies have explored the footprints of membrane-based technologies.

For instance, MBRs were reported to raise better social acceptance, while leaving low 
environmental footprint $[245,246]$ compared to conventional biological treatment methods. Bertanza et al. [247] through the assessment of technical, social, administrative, economic and environmental impacts of full-scale CAS and MBR processes concluded that MBRs have a better social acceptance. However, there is still a need for more studies in order to assess the social perception about membrane-based technologies considering all the aspects of social acceptance of a technology such as the possible drawbacks and positive effects like the potential for creating new jobs, which can highly influence the opinion of the local communities. The adoption of effective tools for awareness of the general public can also play a very significant role in order to reinforce the social acceptability of any industry.

\section{Concluding remarks and future perspectives}

Membrane-based technologies have historically received extensive great deal of attention as the promising methods to deal with the polluted waters. The sustainability of membranebased technologies for the treatment of industrial effluents was assessed in the present study through a systematic review of the developments that have taken place, especially in recent years, and the opportunities to render the technology more sustainable. In this regard, 17 criteria were categorized and discussed in the technical, economic, environmental and social categories. The results of the present review emphasize the need for the development of cheaper membranes, especially using inorganic membranes, in combination with advanced materials such as engineered nanomaterials (e.g., nano-zeolites, metal organic frameworks and carbonbased nanomaterials) in order to meet the future needs for clean water resources.

Combination of MBTs with other methods such as microbial fuel cells to generate energy can also make the treatment process more economically feasible and sustainable. Such advanced methods can considerably contribute to the overcoming of the traditional bottlenecks of membrane technologies (such as fouling properties) to deal with complex industrial effluents in order to focus on further enhancement of effluent quality towards the holistic concept of "one water" approach. At this stage, more studies on sustainability aspects of membrane technologies for the treatment of environmental contaminants will be needed. Technical, environmental, economic and social aspects of new combinations of membrane technologies have to be addressed for accelerating their transferring from the lab-scale and pilot-scale studies to realscale applications. 


\section{Acknowledgment}

Thanks are due, for the financial support to CESAM (UID/AMB/50017), to CICECO-Aveiro Institute of Materials, POCI-01-0145-FEDER-007679 (FCT Ref. UID/CTM/50011/2013), to FCT/MEC through national funds, and the co-funding by the FEDER, within the PT2020 Partnership Agreement and Compete 2020. Thanks, are also due to FCT for the doctoral scholarship No. SFRH/BD/103695/2014 for the first author. Dr. Suhas D.P. is thankful to BJES for awarding "Seed money for research".

\section{References}

[1] S.R. Mudakkar, K. Zaman, M.M. Khan, M. Ahmad, Energy for economic growth, industrialization, environment and natural resources: Living with just enough, Renew. Sustain. Energy Rev. 25 (2013) 580-595. doi:10.1016/j.rser.2013.05.024.

[2] R.C. Olvera, S.L. Silva, E. Robles-Belmont, E.Z. Lau, Review of nanotechnology value chain for water treatment applications in Mexico, Resour. Technol. 3 (2017) 1-11. doi:10.1016/j.reffit.2017.01.008.

[3] L. Zhang, L. Cheng, F. Chiew, B. Fu, Understanding the impacts of climate and landuse change on water yield, Curr. Opin. Environ. Sustain. 33 (2018) 167-174. doi:10.1016/j.cosust.2018.04.017.

[4] X. Feng, Q. Liu, Y. Chen, L. Yin, B. Fu, Linking water research with the sustainability of the human - natural system, Curr. Opin. Environ. Sustain. 33 (2018) 99-103. doi:10.1016/j.cosust.2018.05.012.

[5] C. Tortajada, A.K. Biswas, Achieving universal access to clean water and sanitation in an era of water scarcity: strengthening contributions from academia, Curr. Opin. Environ. Sustain. 34 (2018) 21-25. doi:10.1016/j.cosust.2018.08.001.

[6] A.V.B. Reddy, M. Moniruzzaman, T.M. Aminabhavi, Polychlorinated biphenyls (PCBs) in the environment: Recent updates on sampling, pretreatment, cleanup technologies and their analysis, Chem. Eng. J. 358 (2019) 1186-1207. doi:10.1016/J.CEJ.2018.09.205.

[7] D.S. Fraser, K. O’Halloran, M.R. Van den Heuvel, Toxicity of pulp and paper solid organic waste constituents to soil organisms, Chemosphere. 74 (2009) 660-668. 
doi:10.1016/j.chemosphere.2008.10.065.

[8] M. Ali, T.R. Sreekrishnan, Aquatic toxicity from pulp and paper mill effluents: a review, Adv. Environ. Res. 5 (2001) 175-196. doi:10.1016/S1093-0191(oo)ooo55-1.

[9] M. Kamali, Z. Khodaparast, Review on recent developments on pulp and paper mill wastewater treatment, Ecotoxicol. Environ. Saf. $114 \quad$ (2015) 326-342. doi:10.1016/j.ecoenv.2014.05.005.

[10] P.S. Goh, A.F. Ismail, P.S. Goh, A.F. Ismail, A review on inorganic membranes for desalination and wastewater treatment, Desalination. 434 (2018) 6o-80. doi:10.1016/j.desal.2017.07.023.

[11] J.M.O. Pulido, A review on the use of membrane technology and fouling control for olive mill wastewater treatment, Sci. Total Environ. 563-564 (2016) 664-675. doi:10.1016/j.scitotenv.2015.09.151.

[12] P.S. Goh, A.F. Ismail, P.S. Goh, A.F. Ismail, A review on inorganic membranes for desalination and wastewater treatment, Desalination. 434 (2018) 60-80. doi:10.1016/j.desal.2017.07.023.

[13] A. Sciences, R.P. Soares, Assessment of the performance of three ultra filtration membranes for fractionation of ovine second cheese whey, Int. Dairy J. 48 (2015). doi:10.1016/j.idairyj.2014.12.003.

[14] J.M. Ochando-pulido, S. Rodriguez-vives, G. Hodaifa, A. Martinez-ferez, Impacts of operating conditions on reverse osmosis performance of pretreated olive mill wastewater, Water Res. 46 (2012) 4621-4632. doi:10.1016/j.watres.2012.06.026.

[15] M. Peydayesh, Toraj Mohammadi, O. Bakhtiari, Effective treatment of dye wastewater via positively charged TETA-MWCNT/PES hybrid nanofiltration membranes, Sep. Purif. Technol. 194 (2018) 488-502. doi:10.1016/j.seppur.2017.11.070.

[16] L. Wang, H. Liu, W. Zhang, T. Yu, Q. Jin, B. Fu, H. Liu, Recovery of organic matters in wastewater by self-forming dynamic membrane bioreactor: Performance and membrane fouling, Chemosphere. 203 (2018) 123-131. doi:10.1016/j.chemosphere.2018.03.171.

[17] T. Yan, Y. Ye, H. Ma, Y. Zhang, W. Guo, B. Du, Q. Wei, D. Wei, H.H. Ngo, A critical review on membrane hybrid system for nutrient recovery from wastewater, Chem. Eng. 
J. 348 (2018) 143-156. doi:10.1016/j.cej.2018.04.166.

[18] S. Daguerre-martini, M.B. Vanotti, M. Rodriguez-pastor, A. Rosal, R. Moral, Nitrogen recovery from wastewater using gas-permeable membranes: Impact of inorganic carbon content and natural organic matter, Water Res. 137 (2018) 201-210. doi:10.1016/j.watres.2018.03.013.

[19] S.K. Bhatia, J.L. Smith, Comparative Study of Bubble Point Method and Mercury Intrusion Porosimetry Techniques for Characterizing the Pore-Size Distribution of Geotextiles, Geotextile and Geomembranes. 13 (1994) 679-702. doi:10.1016/o2661144(94)90068-X.

[20] R. Zsigmondy, W. Bachmann, Uber neue Filter, Z.Anorg. Allg. Chem. 103 (1918) 119128. doi:10.1002/zaac.19181030107.

[21] R.W. Baker, Reverse osmosis, in: Membr. Technol. Appl., 2nd ed., John Wiley and Sons, Chichester, UK, UK, 2004. doi:10.1002/0470020393.ch5.

[22] C.E. Reid, E.J. Breton, Water and Ion Flow Across Cellulose Membranes, J. Appl. Polym. Sci. 1 (1959) 133-143. doi:10.1002/14356007.a16_187.pub3.

[23] H. Strathmann, Ullmann's Encyclopedia of Industrial Chemistry, in: Membr. Membr. Sep. Process. 1. Princ., Wiley-VCH Verlag GmbH \& Co. KGaA, Weinheim, 2012: pp. 413456. doi:10.1002/14356007.a16_187.pub3.

[24] X. Zhang, C. Ye, K. Pi, J. Huang, M. Xia, A.R. Gerson, Sustainable treatment of desulfurization wastewater by ion exchange and bipolar membrane electrodialysis hybrid technology, Sep. Purif. Technol. 211 (2019) 330-339. doi:10.1016/j.seppur.2018.10.003.

[25] Sidney Loeb, Production of energy from concentrated brines by pressure-retarded osmosis: I. Preliminary technical and economic correlations, J. Memb. Sci. 1 (1976) 4963. doi:10.1021/bk-1981-0153.cho21.

[26] N.L. Le, S.P. Nunes, Materials and membrane technologies for water and energy $\begin{array}{llllll}\text { sustainability, } & \text { Sustain. } & \text { Mater. Technol. } & 7 & \text { (2016) 1-28. }\end{array}$ doi:10.1016/j.susmat.2016.02.001.

[27] J.E. Cadotte, R.J. Petersen, C. JE., Thin-Film Composite Reverse-Osmosis Membranes: Origin, Development, and Recent Advances, in: A.F. Turbak (Ed.), Synth. Membr. ACS 
Symp. Ser. 153, American Chemical Society, 1981: pp. 305-326. doi:10.1021/bk-19810153.cho21.

[28] S.Avlonitis, W.T.Hanbury, M.BenBoudinar, Spiral wound modules performance an analytical solution: Part II, Desalination. 89 (1993) 227-246. doi:10.1016/oo119164(93)80139-E.

[29] M.I.A.P. Fernandes, Application of porous membranes for biomass retention in a twophase anaerobic reactor, University of Newcastle, 1986.

[30] M.I.A. Anderson, G.K., Saw, C.B., Fernandes, Application of porous membranes for biomass retention in biological wastewater treatment processes, Process Biochem. December (1986) 174-182.

[31] W.J. Lau, A.F. Ismail, N. Misdan, M.A. Kassim, A recent progress in thin fi lm composite $\begin{array}{llllll}\text { membrane: } & \text { A }\end{array}$ doi:10.1016/j.desal.2011.04.004.

[32] X.D. Hao, J. Li, M.C.M. Van Loosdrecht, T.Y. Li, A sustainability-based evaluation of membrane bioreactors over conventional activated sludge processes, J. Environ. Chem. Eng. 6 (2018) 2597-2605. doi:10.1016/j.jece.2018.03.050.

[33] B.M.B. Ensano, L. Borea, V. Naddeo, M.D.G. De Luna, V. Belgiorno, Control of emerging contaminants by the combination of electrochemical processes and membrane bioreactors, Env. Sci Pollut Res. 26 (2019) 1103-1112. doi:10.1007/s11356-017-9097-z.

[34] G. Skouteris, D. Hermosilla, P. López, C. Negro, Á. Blanco, Anaerobic membrane bioreactors for wastewater treatment: A review, Chem. Eng. J. 198-199 (2012) 138-148. doi:10.1016/j.cej.2012.05.070.

[35] H. Ozgun, R. Kaan, M. Evren, C. Kinaci, H. Spanjers, J.B. Van Lier, A review of anaerobic membrane bioreactors for municipal wastewater treatment: Integration options , limitations and expectations, Sep. Purif. Technol. 118 (2013) 89-104. doi:10.1016/j.seppur.2013.06.036.

[36] Y. Hu, X.C. Wang, H.H. Ngo, Q. Sun, Y. Yang, Anaerobic dynamic membrane bioreactor (AnDMBR) for wastewater treatment: A review, Bioresour. Technol. 247 (2018) 11071118. doi:10.1016/j.biortech.2017.09.101. 
[37] World Commission on Environment and Development (WCED), Our Common Future, Oxford University Press, New York, NY, USA, 1987.

[38] C. Chen, Guidance on the Conceptual Design of Sustainable Product - Service Systems, Sustainability. 10 (2018) 2452. doi:10.3390/su10072452.

[39] K. Mori, A. Christodoulou, Review of sustainability indices and indicators: Towards a new City Sustainability Index (CSI), Environ. Impact Assess. Rev. 32 (2012) 94-106. doi:10.1016/j.eiar.2011.06.001.

[40] M. Kamali, A.A. Alesheikh, Z. Khodaparast, S. Mahmoud, S.M.S.M. Hosseinniakani, S.A. Alavi Borazjani, S.A. AlaviBorazjani, Application of Delphi-AHP and Fuzzy-GIS approaches for site selection of large extractive industrial units in Iran, J. Settlements Spat. Plan. 6 (2015) 1-7. doi:10.24193/JSSP.2017.2.03.

[41] P. Arroyo, M. Molinos-Senante, Selecting appropriate wastewater treatment technologies using a choosing-by-advantages approach, Sci. Total Environ. 625 (2018) 819-827. doi:10.1016/j.scitotenv.2017.12.331.

[42] M. Dursun, A fuzzy approach for the assessment of wastewater treatment alternatives, Eng. Lett. 24 (2016) 231-236.

[43] Z. Chen, D. Wang, M. Sun, H. Hao, W. Guo, G. Wu, Sustainability evaluation and implication of a large scale membrane bioreactor plant, Bioresour. Technol. 269 (2019) 246-254. doi:10.1016/j.biortech.2018.08.107.

[44] R.A. Tufa, Perspectives on environmental ethics in sustainability of membrane based technologies for water and energy production, Environ. Technol. Innov. 4 (2015) 182193. doi:10.1016/j.eti.2015.07.003.

[45] S. Mahmood, N.S. Jiran, M.Z.M. Saman, M.Y. Noordin, Determination of Parameters for Sustainability Assessment of Hollow Fiber Membrane Module Life Cycle, 845 (2014) 724-729. doi:10.4028/www.scientific.net/AMR.845.724.

[46] S.O. Ganiyu, E.D. Van Hullebusch, M. Cretin, G. Esposito, M.A. Oturan, Coupling of membrane filtration and advanced oxidation processes for removal of pharmaceutical residues: A critical review, Sep. Purif. Technol. 156 (2015) 891-914. doi:10.1016/j.seppur.2015.09.059. 
[47] A.R.D. Verliefde, E.R. Cornelissen, S.G.J. Heijman, J.Q.J.C. Verberk, G.L. Amy, B. Van Der Bruggen, J.C. Van Dijk, The role of electrostatic interactions on the rejection of organic solutes in aqueous solutions with nanofiltration, 322 (2008) 52-66. doi:10.1016/j.memsci.2008.05.022.

[48] A.R.D. Verliefde, S.G.J. Heijman, E.R. Cornelissen, G. Amy, B. Van Der Bruggen, J.C. Van Dijk, Influence of electrostatic interactions on the rejection with NF and assessment of the removal efficiency during $\mathrm{NF} / \mathrm{GAC}$ treatment of pharmaceutically active compounds in surface water, Water Res. 41 (2007) 3227-3240. doi:10.1016/j.watres.2007.05.022.

[49] C. Bellona, E. Drewes, The role of membrane surface charge and solute physico-chemical properties in the rejection of organic acids by NF membranes, J. Memb. Sci. 249 (2005) 227-234. doi:10.1016/j.memsci.2004.09.041.

[50] B. Van Der Bruggen, J. Schaep, D. Wilms, C. Vandecasteele, Influence of molecular size, polarity and charge on the retention of organic molecules by nanofiltration, J. Memb. Sci. 156 (1999) 29-41.

[51] D. Zhao, C. Su, G. Liu, Y. Zhu, Z. Gu, Performance and autopsy of nanofiltration membranes at an oil-field wastewater desalination plant, Environ. Sci. Pollut. Res. 26 (2019) 2681-2690. doi:10.1007/s11356-018-3797-x.

[52] L. Braeken, R. Ramaekers, Y. Zhang, G. Maes, B. Van Der Bruggen, C. Vandecasteele, Influence of hydrophobicity on retention in nanofiltration of aqueous solutions containing organic compounds, J. Memb. Sci. 252 (2005) 195-203. doi:10.1016/j.memsci.2004.12.017.

[53] V. Yangali-quintanilla, A. Sadmani, M. Mcconville, M. Kennedy, G. Amy, Rejection of pharmaceutically active compounds and endocrine disrupting compounds by clean and fouled nanofiltration membranes, Water Res. 43 (2009) 2349-2362. doi:10.1016/j.watres.2009.02.027.

[54] A.A. Hussain, S.K. Nataraj, M.E.E. Abashar, I.S. Al-Mutaz, T.M. Aminabhavi, Prediction of physical properties of nanofiltration membranes using experiment and theoretical models, J. Memb. Sci. 310 (2008) 321-336. doi:10.1016/j.memsci.2007.11.005. 
[55] Y. Yoon, G. Amy, J. Chob, N. Her, J. Pellegrino, Transport of perchlorate (Clo4-) through NF and UF membranes*, Desalination. 147 (2002) 11-17.

[56] A. Tiraferri, M. Elimelech, Direct quantification of negatively charged functional groups on membrane surfaces, J. Memb. Sci. 389 (2012) 499-508. doi:10.1016/j.memsci.2011.11.018.

[57] S. Sridhar, B. Smitha, S. Mayor, B. Prathab, T.M. Aminabhavi, Gas permeation properties of polyamide membrane prepared by interfacial polymerization, J. Mater. Sci. 42 (2007) 9392-9401. doi:10.1007/s10853-007-1813-5.

[58] M. Al-Furaiji, N.E. Benes, A. Nijmeijer, J.R. McCutcheon, Use of FO-MD integrated process in the treatment of high salinity oily wastewater, Ind. Eng. Chem. Res. 58 (2019) 956-962. doi:10.1021/acs.iecr.8bo4875.

[59] F. Arsalan, Q. She, A.G. Fane, R.W. Field, Exploring the di ff erences between forward osmosis and reverse osmosis fouling, J. Memb. Sci. 565 (2018) 241-253. doi:10.1016/j.memsci.2018.08.034.

[6o] S.P. Dharupaneedi, S.K. Nataraj, M. Nadagouda, K.R. Reddy, S.S. Shukla, T.M. Aminabhavi, Membrane-based separation of potential emerging pollutants, Sep. Purif. Technol. 210 (2019) 850-866. doi:10.1016/j.seppur.2018.09.003.

[61] S. Kim, K.H. Chu, Y.A.J. Al-Hamadani, C.M. Park, M. Jang, D.H. Kim, M. Yu, J. Heo, Y. Yoon, Removal of contaminants of emerging concern by membranes in water and wastewater: A review, Chem. Eng. J. 335 (2018) 896-914. doi:10.1016/j.cej.2017.11.044.

[62] N.S.A. Mutamim, Z.Z. Noor, M.A.A. Hassan, G. Olsson, Application of membrane bioreactor technology in treating high strength industrial wastewater: a performance review, Desalination. 305 (2012) 1-11. doi:10.1016/j.desal.2012.07.033.

[63] M. Namvar-Mahboub, M. Pakizeh, Development of a novel thin film composite membrane by interfacial polymerization on polyetherimide/modified $\mathrm{SiO} 2$ support for organic solvent nanofiltration, Sep. Purif. Technol. 119 (2013) 35-45. doi:10.1016/j.seppur.2013.09.003.

[64] S.T. S.M., V. P., E. M., Polymeric membrane pervaporation, Int. J. Membr. Sci. Technol. 2 (2015) 56-57. doi:10.1016/j.memsci.2006.10.043. 
[65] J.K. Adewole, A.L. Ahmad, S. Ismail, C.P. Leo, Current challenges in membrane separation of $\mathrm{CO} 2$ from natural gas: A review, Int. J. Greenh. Gas Control. 17 (2013) 4665. doi:10.1016/j.ijggc.2013.04.012.

[66] W.J. Lau, A.F. Ismail, Polymeric nanofiltration membranes for textile dye wastewater treatment: Preparation, performance evaluation, transport modelling, and fouling control-a review, Desalination. 245 (2009) 321-348. doi:10.1016/j.desal.2007.12.058.

[67] S.S. Hosseini, E. Bringas, N.R. Tan, I. Ortiz, M. Ghahramani, M.A. Alaei Shahmirzadi, Recent progress in development of high performance polymeric membranes and materials for metal plating wastewater treatment: A review, J. Water Process Eng. 9 (2016) 78-110. doi:10.1016/j.jwpe.2015.11.005.

[68] J. Zeng, H. Ye, Z. Hu, Application of the hybrid complexation - ultrafiltration process for metal ion removal from aqueous solutions, J. Hazard. Mater. 161 (2009) 1491-1498. doi:10.1016/j.jhazmat.2008.04.123.

[69] R.-S. Juang, R.-C. Shiau, Metal removal from aqueous solutions using chitosanenhanced membrane filtration, J. Memb. Sci. 165 (2000) 159-167. doi:10.1016/So3767388(99)00235-5.

[70] T.A. Otitoju, A.L. Ahmad, B.S. Ooi, Polyvinylidene fluoride (PVDF) membrane for oil rejection from oily wastewater: A performance review, J. Water Process Eng. 14 (2016) 41-59. doi:10.1016/j.jwpe.2016.10.011.

[71] P. Le-clech, V. Chen, T.A.G. Fane, Fouling in membrane bioreactors used in wastewater treatment, J. Memb. Sci. 284 (2006) 17-53. doi:10.1016/j.memsci.2006.08.019.

[72] M. Paul, S.D. Jons, Chemistry and fabrication of polymeric nanofiltration membranes: A review, Polymer (Guildf). 103 (2016) 417-456. doi:10.1016/j.polymer.2016.07.085.

[73] Y. Wang, M. Yong, S. Wei, Y. Zhang, W. Liu, Z. Xu, Performance improvement of hybrid polymer membranes for wastewater treatment by introduction of micro reaction locations, Prog. Nat. Sci. Mater. Int. 28 (2018) 148-159. doi:10.1016/j.pnsc.2018.02.011.

[74] D.S. Muggli, L. Ding, Photocatalytic performance of sulfated TiO2 and Degussa P-25 TiO2 during oxidation of organics, Appl. Catal. B Environ. 32 (2001) 181-194.

[75] K. Tanabe, M. Misono, Y. Ono, H. Hattori, 1 Definition and Classification of Solid Acids 
and Bases, Stud. Surf. Sci. Catal. 51 (1989) 1-3. doi:10.1016/So167-2991(o8)61044-7.

[76] S. Mohsen, S. Gato-trinidad, A. Altaee, The application of pressure-driven ceramic membrane technology for the treatment of industrial wastewaters - A review, Sep. Purif. Technol. 200 (2018) 198-220. doi:10.1016/j.seppur.2018.02.041.

[77] B. Hofs, J. Ogier, D. Vries, E.F. Beerendonk, E.R. Cornelissen, Comparison of ceramic and polymeric membrane permeability and fouling using surface water, Sep. Purif. Technol. 79 (2011) 365-374. doi:10.1016/j.seppur.2011.03.025.

[78] L. Jin, S.L. Ong, H.Y. Ng, Comparison of fouling characteristics in different pore-sized submerged ceramic membrane bioreactors, Water Res. 44 (2010) 5907-5918. doi:10.1016/j.watres.2010.07.014.

[79] A. Dafinov, J. Font, R. Garcia-valls, Processing of black liquors by UF/NF ceramic membranes, Desalination. 173 (2005) 83-90. doi:10.1016/j.desal.2004.07.044.

[8o] M. Kamali, T. Gameiro, M.E.V.M.E. Costa, I. Capela, Anaerobic Digestion of Pulp and Paper Mill Wastes - An Overview of the Developments and Improvement Opportunities, Chem. Eng. J. 298 (2016) 162-182.

[81] M.A. Hubbe, J.R. Metts, D. Hermosilla, M.A. Blanco, L. Yerushalmi, F. Haghighat, P. Lindholm-Lehto, Z. Khodaparast, M. Kamali, A. Elliott, Wastewater treatment and reclamation: A review of pulp and paper industry practices and opportunities, BioResources. 11 (2016). doi:10.1016/j.seppur.2011.07.002.

[82] L.C. Neves, J.B. De Souza, C.M.D.S. Vidal, K.G. Martins, B.L. Managó, Pulp and Paper Mill Effluent Post-Treatment Using Microfiltration and Ultrafiltration Membranes, Cellul. Chem. Technol. 51 (2017) 579-588.

[83] E. Alventosa-deLara, S. Barredo-Damas, M.I. Alcaina-Miranda, M.I. Iborra-Clar, Ultrafiltration technology with a ceramic membrane for reactive dye removal: Optimization of membrane performance, J. Hazard. Mater. 209-210 (2012) 492-500. doi:10.1016/j.jhazmat.2012.01.065.

[84] S. Rezaei, H. Abadi, M. Reza, M. Hemati, F. Rekabdar, T. Mohammadi, Ceramic membrane performance in micro filtration of oily wastewater, Desalination. 265 (2011) 222-228. doi:10.1016/j.desal.2010.07.055. 
[85] K. Dharmalingam, D. Pamu, R. Anandalakshmi, Comparison of solid state synthesis of zinc calcium phosphorous oxide (ZCAP) ceramics under conventional and microwave heating methods, Mater. Lett. 212 (2018) 207-210. doi:10.1016/j.matlet.2017.10.044.

[86] A. Zavabeti, B.Y. Zhang, I.A. de Castro, J.Z. Ou, B.J. Carey, M. Mohiuddin, R.S. Datta, C. Xu, A.P. Mouritz, C.F. McConville, A.P. O’Mullane, T. Daeneke, K. Kalantar-Zadeh, Green Synthesis of Low-Dimensional Aluminum Oxide Hydroxide and Oxide Using Liquid Metal Reaction Media: Ultrahigh Flux Membranes, Adv. Funct. Mater. 1804057 (2018) 1-9. doi:10.1002/adfm.201804057.

[87] M. Kamali, M.E. V. Costa, G. Otero-Irurueta, I. Capela, Ultrasonic irradiation as a green production route for coupling crystallinity and high specific surface area in iron nanomaterials, J. Clean. Prod. 211 (2018) 185-197. doi:10.1016/j.jclepro.2018.11.127.

[88] M. Kamali, K.M. Persson, M.E. Costa, I. Capela, Sustainability criteria for assessing nanotechnology applicability in industrialwastewater treatment: Current status and future outlook, Environ. Int. In press (2019). doi:https://doi.org/10.1016/j.envint.2019.01.055.

[89] W. Li, G. Ling, F. Lei, N. Li, W. Peng, K. Li, H. Lu, Ceramic membrane fouling and cleaning during ultra fi ltration of limed sugarcane juice, Sep. Purif. Technol. 190 (2018) 9-24. doi:10.1016/j.seppur.2017.08.046.

[90] S. Emani, R. Uppaluri, M.K. Purkait, Preparation and characterization of low cost ceramic membranes for mosambi juice clari fi cation, Desalination. 317 (2013) 32-40. doi:10.1016/j.desal.2013.02.024.

[91] M. Din, R. Brquezb, Review of the treatment of seafood processing wastewaters and recovery of proteins therein by membrane separation processes - prospects of the ultrafiltration of wastewaters from the fish meal industry, Desalination. 142 (2002) 2945 .

[92] S.K. Nataraj, K.M. Hosamani, T.M. Aminabhavi, Distillery wastewater treatment by the membrane-based nanofiltration and reverse osmosis processes, Water Res. 40 (2006) 2349-2356. doi:10.1016/j.watres.2006.04.022.

[93] S.K. Nataraj, S. Sridhar, I.N. Shaikha, D.S. Reddy, T.M. Aminabhavi, Membrane-based 
microfiltration/electrodialysis hybrid process for the treatment of paper industry wastewater, Sep. Purif. Technol. 57 (2007) 185-192. doi:10.1016/j.seppur.2007.03.014.

[94] S.K. Nataraj, S. Roy, M.B. Patil, M.N. Nadagouda, W.E. Rudzinski, T.M. Aminabhavi, Cellulose acetate-coated a-alumina ceramic composite tubular membranes for wastewater treatment, Desalination. $281 \quad$ (2011) 348-353. doi:10.1016/j.desal.2011.08.016.

[95] Y. Luo, P. Le-Clech, R.K. Henderson, Simultaneous microalgae cultivation and wastewater treatment in submerged membrane photobioreactors: A review, Algal Res. 24 (2017) 425-437. doi:10.1016/j.algal.2016.10.026.

[96] S. Homaeigohar, M. Elbahri, Graphene membranes for water desalination, Nat. Publ. Gr. (2017) 1-16. doi:10.1038/am.2017.135.

[97] S. Kerdsuwan, S. Patumsawad, Bio-Wastes Potential and Utilization in Thailand BioWastes Potential and Utilization in Thailand, Proc. Int. Symp. EcoTopia Sci. ISETSo7 (2007) 614-616.

[98] S. Fudala-Ksiazek, M. Pierpaoli, A. Luczkiewicz, Efficiency of landfill leachate treatment in a MBR/UF system combined with NF, with a special focus on phthalates and bisphenol A removal, Waste Manag. $78 \quad$ (2018) 94-103. doi:10.1016/j.wasman.2018.05.012.

[99] Y. Jeong, S.W. Hermanowicz, C. Park, Treatment of food waste recycling wastewater using anaerobic ceramic membrane bioreactor for biogas production in mainstream treatment process of domestic wastewater, Water Res. 123 (2017) 86-95. doi:10.1016/j.watres.2017.06.049.

[100] K. Cho, Y. Jeong, K. Won, S. Lee, A.L. Smith, Effects of changes in temperature on treatment performance and energy recovery at mainstream anaerobic ceramic membrane bioreactor for food waste recycling wastewater treatment, Bioresour. Technol. 256 (2018) 137-144. doi:10.1016/j.biortech.2018.02.015.

[101] Y. Peng, Perspectives on technology for landfill leachate treatment, Arab. J. Chem. (2013). doi:10.1016/j.arabjc.2013.09.031.

[102] J. Hashisho, M. El-Fadel, Membrane bioreactor technology for leachate treatment at 
solid waste landfills, Rev. Environ. Sci. Biotechnol. 15 (2016) 441-463. doi:10.1007/s11157-016-9399-5.

[103] Q. Sui, W. Zhao, X. Cao, S. Lu, Z. Qiu, X. Gu, Pharmaceuticals and personal care products in the leachates from a typical landfill reservoir of municipal solid waste in Shanghai, China: Occurrence and removal by a full-scale membrane bioreactor, J. Hazard. Mater. 323 (2017) 99-108. doi:10.1016/j.jhazmat.2016.03.047.

[104] S. Patibandla, J. Jiang, X. Shu, Toxicity assessment of four pharmaceuticals in aquatic environment before and after ferrate (VI) treatment, J. Environ. Chem. Eng. 6 (2018) 3787-3797. doi:10.1016/j.jece.2018.05.024.

[105] K. Affek, M. Załęska-radziwiłł, N. Doskocz, K. Dębek, Mixture toxicity of pharmaceuticals present in wastewater to aquatic organisms, Desalin. Water Treat. 117 (2018) 15-20. doi:10.5004/dwt.2018.21964.

[106] M. Mishra, G.M. N, S. Sarma, V. Tatiparti, S. Mukherji, Assessment of Endocrine Disruption Potential of Selected Pharmaceuticals Using an In-vitro Assay, J. Indian Chem. Soc. 95 (2018) 269-277.

[107] K.K. Ng, X. Shi, Y. Yao, H.Y. Ng, Bio-entrapped membrane reactor and salt marsh sediment membrane bioreactor for the treatment of pharmaceutical wastewater: Treatment performance and microbial communities, Bioresour. Technol. 171 (2014) 265-273. doi:10.1016/j.biortech.2014.08.078.

[108] K.K. Ng, X. Shi, S.L. Ong, H.Y. Ng, Pyrosequencing reveals microbial community profile in anaerobic bio-entrapped membrane reactor for pharmaceutical wastewater treatment, Bioresour. Technol. 200 (2016) 1076-1079. doi:10.1016/j.biortech.2015.10.100.

[109] J. Labanda, J. Llorens, Wool scouring waste treatment by a combination of coagulation flocculation process and membrane separation technology, Chem. Eng. Process. 47 (2008) 1061-1068. doi:10.1016/j.cep.2007.07.010.

[110] Z. Laijiu, D. Ph, D. Bing, Treatment of Wool Scouring Wastewater by Immobilized Chitosan Bio-Membrane, J. Eng. Fiber. Fabr. 8 (2013) 1-5.

[111] V.R. Sankar, S. Chandran, D.P. Pandiyan, Performance assessment, kinetics and modelling of biofilm membrane bio-reactor for the treatment of dairy wastewater, J. 
Environ. Biol. 39 (2018) 565-574. doi:10.22438/jeb/39/5/MRN-736 Journal.

[112] M.C. Collivignarelli, F. Castagnola, M. Sordi, G. Bertanza, Sewage sludge treatment in a thermophilic membrane reactor (TMR): factors affecting foam formation, Environ. Sci. Pollut. Res. 24 (2017) 2316-2325. doi:10.1007/s11356-016-7983-4.

[113] P. Moñino, E. Jiménez, R. Barat, D. Aguado, A. Seco, J. Ferrer, Potential use of the organic fraction of municipal solid waste in anaerobic co-digestion with wastewater in submerged anaerobic membrane technology, Waste Manag. 56 (2016) 158-165. doi:10.1016/j.wasman.2016.07.021.

[114] P. Kumar, N. Sharma, R. Ranjan, S. Kumar, Z.F. Bhat, D.K. Jeong, Perspective of Membrane Technology in Dairy Industry: A Review, Asian Australas. J. Anim. Sci. 26 (2013) 1347-1358. doi:10.5713/ajas.2013.13082.

[115] M. Peter-varbanets, C. Zurbru, C. Swartz, W. Pronk, Decentralized systems for potable water and the potential of membrane technology, Water Res. 43 (2009) 245-265. doi:10.1016/j.watres.2008.10.030.

[116] A. Bick, L. Gillerman, Y. Manor, G. Oron, Economic Assessment of an Integrated Membrane System for Secondary Effluent Polishing for Unrestricted Reuse, Water. (2012) 219-236. doi:10.3390/w4010219.

[117] Y. Luo, P. Le-Clech, R.K. Henderson, Simultaneous microalgae cultivation and wastewater treatment in submerged membrane photobioreactors: A review, Algal Res. 24 (2017) 425-437. doi:10.1016/j.algal.2016.10.026.

[118] F. Gao, Z. Yang, C. Li, G. Zeng, D. Ma, L. Zhou, A novel algal biofilm membrane photobioreactor for attached microalgae growth and nutrients removal from secondary effluent, Bioresour. Technol. 179 (2015) 8-12. doi:10.1016/j.biortech.2014.11.108.

[119] L. Marbelia, M.R. Bilad, I. Passaris, V. Discart, D. Vandamme, A. Beuckels, K. Muylaert, I.F.J. Vankelecom, Membrane photobioreactors for integrated microalgae cultivation and nutrient remediation of membrane bioreactors effluent, Bioresour. Technol. 163 (2014) 228-235. doi:10.1016/j.biortech.2014.04.012.

[120] S. Alzahrani, A.W. Mohammad, N. Hilal, P. Abdullah, O. Jaafar, Comparative study of $\mathrm{NF}$ and RO membranes in the treatment of produced water-Part I: Assessing water 
quality, Desalination. 315 (2013) 18-26. doi:10.1016/j.desal.2012.12.004.

[121] P. Banerjee, T. kumar Dey, S. Sarkar, S. Swarnakar, A. Mukhopadhyay, S. Ghosh, Treatment of cosmetic effluent in different configurations of ceramic UF membrane based bioreactor: Toxicity evaluation of the untreated and treated wastewater using catfish (Heteropneustes fossilis), Chemosphere. $146 \quad$ (2016) 133-144. doi:10.1016/j.chemosphere.2015.12.004.

[122] D. Awfa, M. Ateia, M. Fujii, M.S. Johnson, C. Yoshimura, Photodegradation of pharmaceuticals and personal care products in water treatment using carbonaceousTiO2 composites: A critical review of recent literature, Water Res. 142 (2018) 26-45. doi:10.1016/j.watres.2018.05.036.

[123] G.D. Vuković, A.D. Marinković, M. Čolić, M.D. Ristić, R. Aleksić, A.A. Perić-Grujić, P.S. Uskoković, Removal of cadmium from aqueous solutions by oxidized and ethylenediamine-functionalized multi-walled carbon nanotubes, Chem. Eng. J. 157 (2010) 238-248. doi:10.1016/j.cej.2009.11.026.

[124] C.J. Madadrang, H.Y. Kim, G. Gao, N. Wang, J. Zhu, H. Feng, M. Gorring, M.L. Kasner, S. Hou, Adsorption Behavior of EDTA-Graphene Oxide for Pb (II) Removal, ACS Appl. Mater. Interfaces. 4 (2012) 1186-1193.

[125] G. Crini, P.M. Badot, Application of chitosan, a natural aminopolysaccharide, for dye removal from aqueous solutions by adsorption processes using batch studies: A review of recent literature, Prog. Polym. Sci. 33 (2008) 399-447. doi:10.1016/j.progpolymsci.2007.11.001.

[126] P.O. Boamah, Y. Huang, M. Hua, Q. Zhang, J. Wu, J. Onumah, L.K. Sam-Amoah, Sorption of heavy metal ions onto carboxylate chitosan derivatives-A mini-review, Ecotoxicol. Environ. Saf. 116 (2015) 113-120. doi:10.1016/j.ecoenv.2015.01.012.

[127] C. Li, M. Zhang, C. Song, P. Tao, M. Sun, M. Shao, T. Wang, Enhanced Treatment Ability of Membrane Technology by Integrating an Electric Field for Dye Wastewater Treatment: A Review, J. AOAC Int. 101 (2018) 1341-1352.

[128] P. Canepa, N. Marignetti, U. Rognoni, S. Calgari, Olive mill wastewater treatment by combined membrane processes, Water Res. 22 (1988) 1491-1494. doi:10.1016/o043- 
1354(88)90160-1.

[129] M.G. Buonomenna, J. Bae, Membrane processes and renewable energies, Renew. Sustain. Energy Rev. 43 (2015) 1343-1398. doi:10.1016/j.rser.2014.11.091.

[130] A. Scoma, F. Varela-Corredor, L. Bertin, C. Gostoli, S. Bandini, Recovery of VFAs from anaerobic digestion of dephenolized Olive Mill Wastewaters by Electrodialysis, Sep. Purif. Technol. 159 (2016) 81-91. doi:10.1016/j.seppur.2015.12.029.

[131] M. Stoller, M. Bravi, Critical flux analyses on differently pretreated olive vegetation waste water streams: Some case studies, Desalination. $250 \quad$ (2010) $578-582$. doi:10.1016/j.desal.2009.09.027.

[132] M. Stoller, M. Bravi, Critical flux analyses on differently pretreated olive vegetation waste water streams: Some case studies, Desalination. $250 \quad$ (2010) 578-582. doi:10.1016/j.desal.2009.09.027.

[133] C. Lu, N. Henning, M. Schulz, T.A. Ternes, Electrochemical treatment of iopromide under conditions of reverse osmosis concentrates e Elucidation of the degradation pathway, Water Res. 48 (2014) 237-246. doi:10.1016/j.watres.2013.09.035.

[134] P. Liu, H. Zhang, Y. Feng, F. Yang, J. Zhang, Removal of trace antibiotics from wastewater: A systematic study of nanofiltration combined with ozone-based advanced oxidation processes, Chem. Eng. J. 240 (2014) 211-220. doi:10.1016/j.cej.2013.11.057.

[135] T.E. Doll, F.H.F. Â, Cross-flow microfiltration with periodical back-washing for photocatalytic degradation of pharmaceutical and diagnostic residues - evaluation of the long-term stability of the photocatalytic activity of TiO2, Water Res. 39 (2005) 847-854. doi:10.1016/j.watres.2004.11.029.

[136] A.N.L. Ng, A.S. Kim, A mini-review of modeling studies on membrane bioreactor (MBR) treatment for municipal wastewaters, Desalination. 212 (2007) 261-281. doi:10.1016/j.desal.2006.10.013.

[137] V.C. Sarasidis, K. V Plakas, S.I. Patsios, A.J. Karabelas, Investigation of diclofenac degradation in a continuous photo-catalytic membrane reactor. Influence of operating parameters, Chem. Eng. J. 239 (2014) 299-311. doi:10.1016/j.cej.2013.11.026.

[138] T.Y. Cath, N.T. Hancock, C.D. Lundin, C. Hoppe-Jones, J.E. Drewes, A multi-barrier 
osmotic dilution process for simultaneous desalination and purification of impaired water, J. Memb. Sci. 362 (2010) 417-426. doi:10.1016/j.memsci.2010.06.056.

[139] A. Alturki, J. McDonald, S.J. Khan, F.I. Hai, W.E. Price, L.D. Nghiem, Performance of a novel osmotic membrane bioreactor (OMBR) system: Flux stability and removal of trace organics, Bioresour. Technol. 113 (2012) 201-206. doi:10.1016/j.biortech.2012.01.082.

[140] A.A. Alturki, J.A. McDonald, S.J. Khan, W.E. Price, L.D. Nghiem, M. Elimelech, Removal of trace organic contaminants by the forward osmosis process, Sep. Purif. Technol. 103 (2013) 258-266. doi:10.1016/j.seppur.2012.10.036.

[141] W.C.L. Lay, Q. Zhang, J. Zhang, D. McDougald, C. Tang, R. Wang, Y. Liu, A.G. Fane, Effect of Pharmaceuticals on the Performance of a Novel Osmotic Membrane Bioreactor (OMBR), Sep. Sci. Technol. 47 (2012) 543-554. doi:10.1080/01496395.2011.630249.

[142] H. Nagar, N. Badhrachalam, V.V.B. Rao, S. Sridhar, A novel microbial fuel cell incorporated with polyvinylchloride/4A zeolite composite membrane for kitchen wastewater reclamation and power generation, Mater. Chem. Phys. 224 (2019) 175-185. doi:10.1016/j.matchemphys.2018.12.023.

[143] P.H. Nakhate, N.T. Joshi, K. V. Marathe, A critical review of bioelectrochemical membrane reactor (BECMR) as cutting-edge sustainable wastewater treatment, Rev. Chem. Eng. 33 (2017) 143-161. doi:10.1515/revce-2016-0012.

[144] M. Saleem, M.C. Lavagnolo, G. Concheri, P. Stevanato, A. Squartini, A. Spagni, Application of anaerobic dynamic membrane bioreactor (AnDMBR) for the successful enrichment of Anammox bacteria using mixed anaerobic and aerobic seed sludge, Bioresour. Technol. 266 (2018) 532-540. doi:10.1016/j.biortech.2018.06.100.

[145] Y. Hu, Y. Yang, S. Yu, X.C. Wang, J. Tang, Psychrophilic anaerobic dynamic membrane bioreactor for domestic wastewater treatment: Effects of organic loading and sludge recycling, Bioresour. Technol. 270 (2018) 62-69. doi:10.1016/j.biortech.2018.08.128.

[146] A.L. Smith, L.B. Stadler, L. Cao, N.G. Love, L. Raskin, S.J. Skerlos, Navigating wastewater energy recovery strategies: A life cycle comparison of anaerobic membrane bioreactor and conventional treatment systems with anaerobic digestion, Environ. Sci. Technol. 48 (2014) 5972-5981. doi:10.1021/es5006169. 
[147] A.L. Smith, S.J. Skerlos, L. Raskin, Membrane biofilm development improves COD removal in anaerobic membrane bioreactor wastewater treatment, Microb. Biotechnol. 8 (2015) 883-894. doi:10.1111/1751-7915.12311.

[148] C. Chen, W. Guo, H. Hao, D. Lee, K. Tung, P. Jin, J. Wang, Y. Wu, Challenges in biogas production from anaerobic membrane bioreactors, Renew. Energy. 98 (2016) 120-134. doi:10.1016/j.renene.2016.03.095.

[149] B.D. Shoener, C. Zhong, A.D. Greiner, W.O. Khunjar, P. Hong, J.S. Guest, Design of anaerobic membrane bioreactors for the valorization of dilute organic carbon waste streams ${ }^{\dagger}$, Energy Environ. Sci. 9 (2016) 1102-1112. doi:10.1039/c5eeo3715h.

[150] C. Mamimin, S. Chaikitkaew, C. Niyasom, Effect of operating parameters on process stability of continuous biohydrogen production from palm oil mill effluent under thermophilic condition, Energy Procedia. $79 \quad$ (2015) 815-821. doi:10.1016/j.egypro.2015.11.571.

[151] D.B. Miklos, R. Hartl, P. Michel, K.G. Linden, U. Hübner, UV/H2O2 process stability and pilot-scale validation for trace organic chemical removal from wastewater treatment plant ef fl uents, Water Res. 136 (2018) 169-179. doi:10.1016/j.watres.2018.02.044.

[152] F. Ahmed, B. Singh, V. Kochkodan, N. Hilal, R. Hashaikeh, Electrically conductive polymeric membranes for fouling prevention and detection: A review, Desalination. 391 (2016) 1-15. doi:10.1016/j.desal.2016.01.030.

[153] D. Breite, M. Went, A. Prager, A. Schulze, The critical zeta potential of polymer membranes: how electrolytes impact membrane fouling, RSC Adv. (2016) 9818098189. doi:10.1039/c6ra19239d.

[154] V. Kochkodan, D.J. Johnson, N. Hilal, Polymeric membranes : Surface modi fi cation for minimizing ( bio ) colloidal fouling, Adv. Colloid Interface Sci. 206 (2014) 116-140. doi:10.1016/j.cis.2013.05.005.

[155] S.H. Mohamad, M.I. Idris, H.Z. Abdullah, A.F. Ismail, Short Review of Ultrafiltration of Polymer Membrane as a Self-Cleaning and Antifouling in the Wastewater System, Adv. Mater. Res. 795 (2013) 318-323. doi:10.4028/www.scientific.net/AMR.795.318.

[156] D. Tang, R. Yuan, Y. Chai, Magnetic control of an electrochemical microfluidic device 
with an arrayed immunosensor for simultaneous multiple immunoassays, Clin. Chem. 53 (2007) 1323-1329. doi:10.1373/clinchem.2006.085126.

[157] J. Li, S. Guo, Z. Xu, J. Li, Z. Pan, Z. Du, F. Cheng, Preparation of omniphobic PVDF membranes with silica nanoparticles for treating coking wastewater using direct contact membrane distillation: Electrostatic adsorption vs. chemical bonding, J. Memb. Sci. 574 (2019) 349-357. doi:10.1016/j.memsci.2018.12.079.

[158] S. Yang, S. Choi, S.M. Jeon, J. Yu, Silica nanoparticle stability in biological media revisited, Sci. Rep. (2018) 1-9. doi:10.1038/s41598-017-18502-8.

[159] C.O. Metin, L.W. Lake, C.R. Miranda, Q.P. Nguyen, Stability of aqueous silica nanoparticle dispersions Stability of Aqueous Silica Nanoparticle Dispersions under Subsurface Conditions, J. Nanoparticle Res. 13 (2011) 839-850. doi:10.1007/s11051010-0085-1.

[160] S. Zhang, R. Wang, S. Zhang, G. Li, Y. Zhang, Development of phosphorylated silica nanotubes (PSNTs)/polyvinylidene fluoride (PVDF) composite membranes for wastewater treatment, Chem. Eng. J. $230 \quad$ (2013) 260-271. doi:10.1016/j.cej.2013.06.098.

[161] S. Zhang, R. Wang, S. Zhang, G. Li, Y. Zhang, Treatment of wastewater containing oil using phosphorylated silica nanotubes (PSNTs)/polyvinylidene fluoride (PVDF) composite membrane, Desalination. 332 (2014) 109-116. doi:10.1016/j.desal.2013.11.008.

[162] X. Zhao, Y. Su, Y. Liu, R. Zhang, Z. Jiang, Multiple antifouling capacities of hybrid membranes derived from multifunctional titania nanoparticles, J. Memb. Sci. 495 (2015) 226-234. doi:10.1016/j.memsci.2015.08.026.

[163] H. Shahbeig, M. Reza, H. Reza, M. Rezaei, Role of zeolite in reducing membrane fouling in a hybrid membrane bioreactor system applied for wastewater treatment, Desalin. Water Treat. 98 (2017) 21673. doi:10.5004/dwt.2017.21673.

[164] I. Chang, S.J. Judd, Domestic wastewater treatment by a submerged MBR (membrane bio-reactor) with enhanced air sparging, Water Sci. Technol. 47 (2018) 149-154.

[165] F. José, C. Braga, S. Ota, A. Augusto, C. Universitária, S.P. Sp, Characterization of 
PVDF/HAP composites for medical applications, Mater. Res. 10 (2007) 247-251.

[166] C. Geraci, D. Heidel, C. Sayes, L. Hodson, P. Schulte, A. Eastlake, S. Brenner, Perspectives on the design of safer nanomaterials and manufacturing processes, $\mathrm{J}$ Nanopart Res. 17 (2015) 366-387. doi:10.1007/s11051-015-3152-9.

[167] M. Khalaj, M. Kamali, Z. Khodaparast, A. Jahanshahi, Copper-based nanomaterials for environmental decontamination - An overview on technical and toxicological aspects, Ecotoxicol. Environ. Saf. 148 (2018) 813-824. doi:10.1016/j.ecoenv.2017.11.06o.

[168] M. Ema, M. Gamo, K. Honda, A review of toxicity studies on graphene-based nanomaterials in laboratory animals, Regul. Toxicol. Pharmacol. 85 (2017) 7-24. doi:10.1016/j.yrtph.2017.01.011.

[169] M. Shakeel, F. Jabeen, S. Shabbir, M.S. Asghar, M.S. Khan, A.S. Chaudhry, Toxicity of Nano-Titanium Dioxide (TiO2-NP) Through Various Routes of Exposure: a Review, Biol. Trace Elem. Res. 172 (2016) 1-36. doi:10.1007/s12011-015-0550-x.

[170] J.C. Lai, M.B. Lai, S. Jandhyam, V.V. Dukhande, A. Bhushan, C.K. Daniels, S.W. Leung, Exposure to titanium dioxide and other metallic oxide nanoparticles induces cytotoxicity on human neural cells and fibroblasts, Int. J. Nanomedicine. 3 (2008) 533-545.

[171] C.R. Walters, E.J. Pool, V.S. Somerset, Ecotoxicity of silver nanomaterials in the aquatic environment: A review of literature and gaps in nano-toxicological research, J. Environ. Sci. Heal. - Part A Toxic/Hazardous Subst. Environ. Eng. 49 (2014) 1588-1601. doi:10.1080/10934529.2014.938536.

[172] C. Som, P. Wick, H. Krug, B. Nowack, Environmental and health effects of nanomaterials in nanotextiles and façade coatings., Environ. Int. 37 (2011) 1131-42. doi:10.1016/j.envint.2011.02.013.

[173] T.L. Rocha, N.C. Mestre, S.M.T. Sabóia-Morais, M.J. Bebianno, Environmental behaviour and ecotoxicity of quantum dots at various trophic levels: A review, Environ. Int. 98 (2017) 1-17. doi:10.1016/j.envint.2016.09.021.

[174] S. Glisovic, D. Pesic, E. Stojiljkovic, T. Golubovic, D. Krstic, M. Prascevic, Z. Jankovic, Emerging technologies and safety concerns: a condensed review of environmental life cycle risks in the nano-world, Int. J. Environ. Sci. Technol. 14 (2017) 2301-2320. 
doi:10.1007/s13762-017-1367-2.

[175] M. Kamali, A.P.D. Gomes, Z. Khodaparast, T. Seifi, Review on recent advances in environmental remediation and related toxicity of engineered nanoparticles, Environ. Eng. Manag. J. 15 (2016) 923-934.

[176] J. Ren, H. Liang, F.T.S. Chan, Urban sewage sludge, sustainability, and transition for Eco-City: Multi-criteria sustainability assessment of technologies based on best-worst method, Technol. Forecast. Soc. Change. $116 \quad$ (2017) 29-39. doi:10.1016/j.techfore.2016.10.070.

[177] M. Molinos-Senante, F. Hernández-Sancho, R. Sala-Garrido, Economic feasibility study for wastewater treatment: A cost-benefit analysis, Sci. Total Environ. 408 (2010) 43964402. doi:10.1016/j.scitotenv.2010.07.014.

[178] M. Molinos-Senante, M. Garrido-Baserba, R. Reif, F. Hernández-Sancho, M. Poch, Assessment of wastewater treatment plant design for small communities: Environmental and economic aspects, Sci. Total Environ. 427-428 (2012) 11-18. doi:10.1016/j.scitotenv.2012.04.023.

[179] P.P. Kalbar, S. Karmakar, S.R. Asolekar, Selection of an appropriate wastewater treatment technology: A scenario-based multiple-attribute decision-making approach, J. Environ. Manage. 113 (2012) 158-169. doi:10.1016/j.jenvman.2012.08.025.

[180] B. Jozsef, P. Blaga, Production cost optimization in industrial wastewater treatment, Procedia Econ. Financ. 15 (2014) 1463-1469. doi:10.1016/S2212-5671(14)oo612-1.

[181] N. Buyukkamaci, E. Koken, Economic evaluation of alternative wastewater treatment plant options for pulp and paper industry, Sci. Total Environ. 408 (2010) 6070-6078. doi:10.1016/j.scitotenv.2010.08.045.

[182] J.M. Ochando-pulido, G. Hodaifa, M.D. Victor-ortega, A. Martínez-ferez, Fouling control by threshold fl ux measurements in the treatment of different olive mill wastewater streams by membranes-in-series process, Desalination. 343 (2014) 162-168. doi:10.1016/j.desal.2013.10.002.

[183] A.K. Basumatary, R.V. Kumar, A.K. Ghoshal, G. Pugazhenthi, Cross flow ultra filtration of Cr (VI) using MCM-41, MCM-48 and Faujasite (FAU) zeolite-ceramic composite 
membranes, $\quad$ Chemosphere. $\quad 153 \quad$ (2016) 436-446. doi:10.1016/j.chemosphere.2016.03.077.

[184] M. Gierszewska, J. Ostrowska-czubenko, Chitosan-based membranes with different ionic crosslinking density for pharmaceutical and industrial applications, Carbohydr. Polym. 153 (2016) 501-511. doi:10.1016/j.carbpol.2016.07.126.

[185] L. Zhu, M. Chen, Y. Dong, C.Y. Tang, A. Huang, A low-cost mullite-titania composite ceramic hollow fi ber micro fi ltration membrane for highly ef fi cient separation of oilin- water emulsion, Water Res. 90 (2016) 277-285. doi:10.1016/j.watres.2015.12.035.

[186] J.R. Scheibler, Everton Ranny Ferreira Santos, A.S. Barbosa, M.G.F. Rodrigues, Performance of zeolite membrane (ZSM-5/ $\mathrm{Y}$-Alumina) in the oil/water separation process, Desalin. Water Treat. 56 (2015) 3561-3567.

[187] S. Long, L. Zhao, T. Shi, J. Li, J. Yang, H. Liu, G. Mao, Z. Qiao, Y. Yang, Pollution control and cost analysis of wastewater treatment at industrial parks in Taihu and Haihe water basins, China, J. Clean. Prod. 172 (2018) 2435-2442. doi:10.1016/j.jclepro.2017.11.167.

[188] O.K. Abass, X. Wu, Y. Guo, K. Zhang, Membrane Bioreactor in China: A Critical Review, Int. J. Membr. Sci. Technol. 2 (2015) 29-47. doi:10.15379/2410-1869.2015.02.02.04.

[189] S.E. Weschenfelder, A.C.C. Mello, C.P. Borges, J.C. Campos, Oilfield produced water treatment by ceramic membranes: Preliminary process cost estimation, Desalination. $360(2015) 81-86$.

[190] E. Environ, M.M. Pendergast, E.M. V Hoek, Environmental Science REVIEW A review of water treatment membrane nanotechnologies, Energy Environ. Sci. 4 (2011) 1946-1971. doi:10.1039/coeeoo541j.

[191] X. Zhang, Y. Liu, Halogenated organics generated during online chemical cleaning of MBR : An emerging threat to water supply and public health, Sci. Total Environ. 656 (2019) 547-549. doi:10.1016/j.scitotenv.2018.11.410.

[192] S.S. Madaenl, T. Mohamamdi, M. Kazemi, Chemical cleaning of reverse osmosis membranes, Desalination. 134 (2001) 77-82.

[193] P. Van Den Brink, F. Vergeldt, H. Van As, A. Zwijnenburg, H. Temmink, M.C.M. Van Loosdrecht, Potential of mechanical cleaning of membranes from a membrane 
bioreactor, J. Memb. Sci. 429 (2013) 259-267. doi:10.1016/j.memsci.2012.11.061.

[194] M. Aslam, A. Charfi, G. Lesage, M. Heran, J. Kim, Membrane bioreactors for wastewater treatment: A review of mechanical cleaning by scouring agents to control membrane fouling, Chem. Eng. J. 307 (2017) 897-913. doi:10.1016/j.cej.2016.08.144.

[195] M. Bagheri, S. Ahmad, Critical review of fouling mitigation strategies in membrane bioreactors treating water and wastewater, Bioresour. Technol. 258 (2018) 318-334. doi:10.1016/j.biortech.2018.03.026.

[196] McGraw-Hill, S.P. Parker, McGraw-Hill Dictionary of Scientific and Technical Terms, 6th ed., McGraw-Hill Professional Publishing, New York City, 2002.

[197] G. Han, Z.L. Cheng, T. Chung, Thin-film composite (TFC) hollow fiber membrane with double-polyamide active layers for internal concentration polarization and fouling mitigation in osmotic processes, J. Memb. Sci. 523 (2017) 497-504. doi:10.1016/j.memsci.2016.10.022.

[198] J.M. Ochando-pulido, V. Verardo, A. Segura-carretero, A. Martinez-ferez, Journal of Industrial and Engineering Chemistry Analysis of the concentration polarization and fouling dynamic resistances under reverse osmosis membrane treatment of olive mill wastewater, J. Ind. Eng. Chem. 31 (2015) 132-141. doi:10.1016/j.jiec.2015.06.017.

[199] H. Yuan, Z. He, Integrating membrane filtration into bioelectrochemical systems as next generation energy-efficient wastewater treatment technologies for water reclamation: A review, Bioresour. Technol. 195 (2015) 202-209. doi:10.1016/j.biortech.2015.05.058.

[200] S. Huang, R.H.A. Ras, X. Tian, Antifouling membranes for oily wastewater treatment: Interplay between wetting and membrane fouling, Curr. Opin. Colloid Interface Sci. 36 (2018) 90-109. doi:10.1016/j.cocis.2018.02.002.

[201] B. Wu, R. Wang, A.G. Fane, The roles of bacteriophages in membrane-based water and wastewater treatment processes: A review, Water Res. 110 (2017) 120-132. doi:10.1016/j.watres.2016.12.004.

[202] A. Hospido, I. Sanchez, G. Rodriguez-garcia, A. Iglesias, D. Buntner, R. Reif, M.T. Moreira, G. Feijoo, Are all membrane reactors equal from an environmental point of view ?, Desalination. 285 (2012) 263-270. doi:10.1016/j.desal.2011.10.011. 
[203] W. Zhang, L. Ding, J. Luo, M.Y. Jaffrin, B. Tang, Membrane fouling in photocatalytic membrane reactors (PMRs) for water and wastewater treatment: A critical review, Chem. Eng. J. 302 (2016) 446-458. doi:10.1016/j.cej.2016.05.071.

[204] X. Su, Y. Tian, Z. Sun, Y. Lu, Z. Li, Performance of a combined system of microbial fuel cell and membrane bioreactor: Wastewater treatment, sludge reduction, energy recovery and membrane fouling, Biosens. Bioelectron. 49 (2013) 92-98. doi:10.1016/j.bios.2013.04.005.

[205] X. Wang, X. Wang, L. Zhang, Q. An, H. Chen, X. Wang, X. Wang, L. Zhang, Q. An, H. Chen, H. Chen, Morphology and Formation Mechanism of Poly(Vinylidene Fluoride) Membranes Prepared with Immerse Precipitation: Effect of Dissolving Temperature, J. Macromol. Sci. Part B. 2348 (2009) 696-709. doi:10.1080/00222340902958950.

[206] I.A. Ike, J. Zhang, A. Groth, J.D. Orbell, M. Duke, Effects of dissolution conditions on the properties of PVDF ultrafiltration membranes, Ultrason. - Sonochemistry. 39 (2017) 716-726. doi:10.1016/j.ultsonch.2017.05.041.

[207] D.J. Lin, K. Beltsios, T.H. Young, Y.S. Jeng, L.P. Cheng, Strong effect of precursor preparation on the morphology of semicrystalline phase inversion poly(vinylidene fluoride) membranes, J. Memb. Sci. $274 \quad$ (2006) 64-72. doi:10.1016/j.memsci.2005.07.043.

[208] A.S. Adeleye, J.R. Conway, T. Perez, P. Rutten, A.A. Keller, Influence of Extracellular Polymeric Substances on the Long-Term Fate, Dissolution, and Speciation of CopperBased Nanoparticles, Environ. Sci. Technol. 48 (2014) 12561-12568.

[209] I.A. Mudunkotuwa, T. Rupasinghe, C.-M. Wu, V.H. Grassian, Dissolution of ZnO Nanoparticles at Circumneutral pH: A Study of Size Effects in the Presence and Absence of Citric Acid, Langmuir. 28 (2012) 396-403.

[210] J. Schmidt, W. Vogelsberger, Aqueous Long-Term Solubility of Titania Nanoparticles and Titanium(IV) Hydrolysis in a Sodium Chloride System Studied by Adsorptive Stripping Voltammetry, J. Solution Chem. 38 (2009) 1267-1282.

[211] Y.J. Chan, M.F. Chong, C.L. Law, D.G. Hassell, A review on anaerobic - aerobic treatment of industrial and municipal wastewater, Chem. Eng. J. 155 (2009) 1-18. 
[212] K. Engels, E. Sanganyado, E. Bere, B. Yalala, Adsorption of sugarcane vinasse e ffl uent on bagasse fl y ash : A parametric and kinetic study, J. Environ. Manage. 224 (2018) 182-190. doi:10.1016/j.jenvman.2018.07.042.

[213] C. Zaharia, Discoloration of industrial effluents by adsorption-based treatment onto coal fly ash activated with lime, Desalin. Water Treat. $127 \quad$ (2018) 22786. doi:10.5004/dwt.2018.22786.

[214] M. Kamali, I. Capela, M.E. Costa, Ultrasonic Synthesis of Zero Valent Iron Nanoparticles for the Efficient Discoloration of Aqueous Solutions Containing Methylene Blue Dye, in: S. Ul-Islam, B.S. Butola (Eds.), Nanomater. Wet Process. Text., Wiley, 2018: pp. 261284 .

[215] M. Abdulmunem, M. Ha, D. Othman, A. Fauzi, T. Matsuura, Z. Harun, M.A. Rahman, Carbon dioxide capture using a superhydrophobic ceramic hollow fi bre membrane for gas-liquid contacting process, J. Clean. Prod. $140 \quad$ (2017) 1731-1738. doi:10.1016/j.jclepro.2016.07.015.

[216] T. Melin, B. Jefferson, D. Bixio, C. Thoeye, W. De Wilde, J. De Koning, Membrane bioreactor technology for wastewater treatment and reuse, Desalination. 187 (2006) 271-282. doi:10.1016/j.desal.2005.04.086.

[217] J. Dasgupta, J. Sikder, S. Chakraborty, S. Curcio, E. Drioli, Remediation of textile effluents by membrane based treatment techniques: A state of the art review, J. Environ. Manage. 147 (2015) 55-72. doi:10.1016/j.jenvman.2014.08.0o8.

[218] K. Ranganathan, K. Karunagaran, D.C. Sharma, Recycling of wastewaters of textile dyeing industries using advanced treatment technology and cost analysis - Case studies, Resour. Conserv. Recycl. 50 (2007) 306-318. doi:10.1016/j.resconrec.2006.06.004.

[219] A. Fakhru, A. Pendashteh, Z. Zainal, L. Chuah, D. Radiah, A. Biak, S. Siavash, Application of membrane-coupled sequencing batch reactor for oilfield produced water recycle and beneficial re-use, Bioresour. Technol. 101 (2010) 6942-6949. doi:10.1016/j.biortech.2010.04.005.

[220] P. Krzeminski, L. Leverette, S. Malamis, E. Katsou, Membrane bioreactors - A review on recent developments in energy reduction, fouling control, novel con fi gurations, LCA 
and market prospects, J. Memb. Sci. 527 (2017) 207-227. doi:10.1016/j.memsci.2016.12.010.

[221] T. Jeppesen, L. Shu, G. Keir, V. Jegatheesan, Metal recovery from reverse osmosis concentrate, J. Clean. Prod. 17 (2009) 703-707. doi:10.1016/j.jclepro.2008.11.013.

[222] M.A. Barakat, New trends in removing heavy metals from industrial wastewater, Arab. J. Chem. 4 (2011) 361-377. doi:10.1016/j.arabjc.2010.07.019.

[223] D. Humpert, M. Ebrahimi, P. Czermak, Membrane Technology for the Recovery of Lignin: A Review, Membranes (Basel). 6 (2016) 1-13. doi:10.3390/membranes6030042.

[224] V. Jegatheesan, B.K. Pramanik, J. Chen, D. Navaratna, C.Y. Chang, L. Shu, Treatment of textile wastewater with membrane bioreactor: A critical review, Bioresour. Technol. 204 (2016) 202-212. doi:10.1016/j.biortech.2016.01.006.

[225] R. Garc1, L. Sua, Journal of Industrial and Engineering Chemistry Membrane technology for the recovery of detergent compounds : A review, J. Ind. Eng. Chem. 18 (2012) 18591873. doi:10.1016/j.jiec.2012.05.015.

[226] A. D’Angelo, M. Tedesco, A. Cipollina, A. Galia, G. Micale, O. Scialdone, Reverse electrodialysis performed at pilot plant scale: Evaluation of redox processes and simultaneous generation of electric energy and treatment of wastewater, Water Res. 125 (2017) 123-131. doi:10.1016/j.watres.2017.08.008.

[227] F.C. Yen, S.J. You, T.C. Chang, Performance of electrodialysis reversal and reverse osmosis for reclaiming wastewater from high-tech industrial parks in Taiwan: A pilot$\begin{array}{lllllll}\text { scale study, J. } & \text { Environ. }\end{array}$ doi:10.1016/j.jenvman.2016.11.001.

[228] M.S.M. Mansour, H.I. Abdel-Shafy, F.M.S. Mehaya, Valorization of food solid waste by recovery of polyphenols using hybrid molecular imprinted membrane, J. Environ. Chem. Eng. 6 (2018) 4160-4170. doi:10.1016/j.jece.2018.06.019.

[229] M. Kamali, M.E. Costa, I. Capela, Nitrate Removal and Nitrogen Sequestration from Polluted Waters Using Zero-Valent Iron Nanoparticles Synthesized under Ultrasonic Irradiation, in: Adv. Mater. Wastewater Treat., John Wiley \& Sons, Inc., Hoboken, NJ, USA., 2017: pp. 479-505. doi:10.1002/9781119407805.ch13. 
[230] J. Tholen, B. Brand, E. van Schaick, Membrane technology: Recovery of waste and water with membranes, Filtr. Sep. 46 (2009) 28-29. doi:10.1016/Soo15-1882(09)70035-7.

[231] A. Cano, C. Palet, Xylooligosaccharide recovery from agricultural biomass waste treatment with enzymatic polymeric membranes and characterization of products with MALDI-TOF-MS, J. Memb. Sci. 291 (2007) 96-105. doi:10.1016/j.memsci.2006.12.048.

[232] A. Ronteltap, A.R.H. Fischer, H. Tobi, Societal response to nanotechnology: Converging technologies-converging societal response research?, J. Nanoparticle Res. 13 (2011) 4399-4410. doi:10.1007/s11051-011-0473-1.

[233] S. Liu, Q. Ma, B. Wang, Advanced treatment of refractory organic pollutants in petrochemical industrial wastewater by bioactive enhanced ponds and wetland system, Ecotoxicology. 23 (2014) 689-698. doi:10.1007/s10646-014-1215-9.

[234] L. Schideman, V.L. Snoeyink, B.J. Mariñas, M. Kosterman, Pilot plant study on the performance and optimization of submerged membranes for taste and odor removal, Water Sci. Technol. Water Supply. 2 (2002) 185-192.

[235] M. Son, D.G. Cho, J.H. Lim, J. Park, S. Hong, H.J. Ko, T.H. Park, Real-time monitoring of geosmin and 2-methylisoborneol, representative odor compounds in water pollution using bioelectronic nose with human-like performance, Biosens. Bioelectron. 74 (2015) 199-206. doi:10.1016/j.bios.2015.06.053.

[236] P.A. Garc1, R. Lebrero, A.C. Gondim, R. Pe, Comparative assessment of a biofilter, a biotrickling filter and a hollow fiber membrane bioreactor for odor treatment in wastewater treatment plants, Water Res. 9 (2014) 339-350. doi:10.1016/j.watres.2013.09.055.

[237] J.R. Mccutcheon, M. Elimelech, Influence of concentrative and dilutive internal concentration polarization on flux behavior in forward osmosis, J. Memb. Sci. 284 (2006) 237-247. doi:10.1016/j.memsci.2006.07.049.

[238] A. Bruchet, J.M. Laîné, Efficiency of membrane processes for taste and odor removal, Water Sci. Technol. 51 (2005) 257-265. doi:013-17-193-X.

[239] A.P. Trzcinski, M.J. Ray, D.C. Stuckey, Performance of a three-stage membrane bioprocess treating the organic fraction of municipal solid waste and evolution of its 
archaeal and bacterial ecology, Bioresour. Technol. 101 (2010) 1652-1661. doi:10.1016/j.biortech.2009.09.075.

[240] J.-P. Zock, R. Verheij, M. Helbich, B. Volker, P. Spreeuwenberg, M. Strak, N.A.H. Janssen, M. Dijst, P. Groenewegen, The impact of social capital, land use, air pollution and noise on individual morbidity in Dutch neighbourhoods, Environ. Int. 121 (2018) 453-460. doi:10.1016/J.ENVINT.2018.09.008.

[241] B. De Heyder, P.Ockier, R. Jansen, R. Huiberts, Predicting the sound power and impact of a wastewater treatment plant, Water Sci Technol. 44 (2001) 235-241.

[242] A. Woodson-Boulton, "Industry without art is brutality": Aesthetic ideology and social practice in Victorian art museums, J. Br. Stud. 46 (2007) 47-71.

[243] J. Ren, D. Xu, H. Cao, S. Wei, L. Dong, M.E. Goodsite, Sustainability decision support framework for industrial system prioritization, Process Syst. Eng. 62 (2016) 108-130.

[244] N. Gupta, A.R.H. Fischer, I.A. Van Der Lans, L.J. Frewer, Factors influencing societal response of nanotechnology: An expert stakeholder analysis, J. Nanoparticle Res. 14 (2012). doi:10.1007/s11051-012-0857-X.

[245] L. Ioannou-ttofa, S. Foteinis, E. Chatzisymeon, D. Fatta-kassinos, Science of the Total Environment The environmental footprint of a membrane bioreactor treatment process through Life Cycle Analysis, Sci. Total Environ. 568 (2016) 306-318. doi:10.1016/j.scitotenv.2016.06.032.

[246] R. Pretel, A. Robles, M. V Ruano, A. Seco, J. Ferrer, Economic and environmental sustainability of submerged anaerobic MBR-based (AnMBR-based) technology as compared to aerobic-based technologies for moderate-/high-loaded urban wastewater treatment, J. Environ. Manage. 166 (2016) 45-54. doi:10.1016/j.jenvman.2015.10.004.

[247] G. Bertanza, M. Canato, G. Laera, M. Vaccari, M. Svanström, S. Heimersson, A comparison between two full-scale MBR and CAS municipal wastewater treatment plants: techno-economic-environmental assessment, Environ. Sci. Pollut. Res. 24 (2017) 17383-17393. doi:10.1007/s11356-017-9409-3. 
Supplementary Material
Click here to download Supplementary Material: Suplementary material.docx

Supplementary Material
Click here to download Supplementary Material: Suplementary material.docx

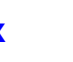

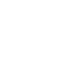

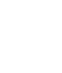

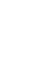

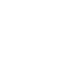

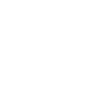

(

.

(

.

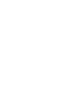

(

.

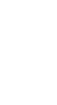

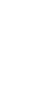

.

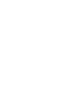

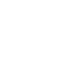

.

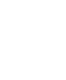

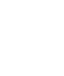

更

更

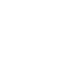

更

更

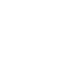

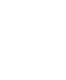

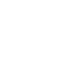

更

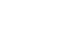

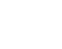

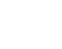

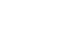

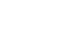

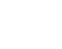

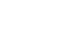

